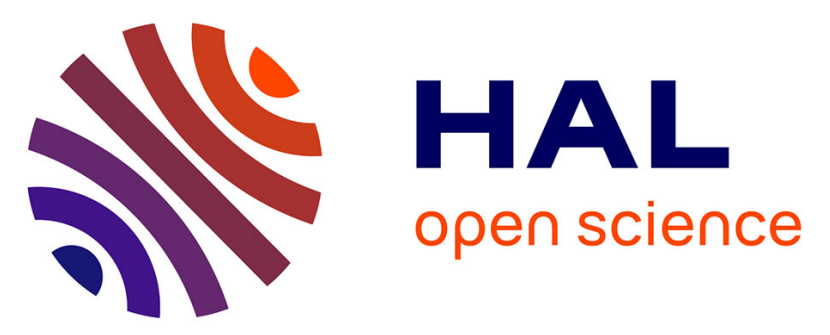

\title{
L'occupation protohistorique de la Grotte Suspendue de Collias (Gard)
}

\author{
André Coste, Bernard Dedet, Xavier Gutherz, Michel Py
}

\section{To cite this version:}

André Coste, Bernard Dedet, Xavier Gutherz, Michel Py. L'occupation protohistorique de la Grotte Suspendue de Collias (Gard). Gallia - Fouilles et monuments archéologiques en France métropolitaine, 1976, 34 (1), pp.129-166. 10.3406/galia.1976.1547 . hal-01926397

\section{HAL Id: hal-01926397 \\ https://hal.science/hal-01926397}

Submitted on 4 Feb 2020

HAL is a multi-disciplinary open access archive for the deposit and dissemination of scientific research documents, whether they are published or not. The documents may come from teaching and research institutions in France or abroad, or from public or private research centers.
L'archive ouverte pluridisciplinaire HAL, est destinée au dépôt et à la diffusion de documents scientifiques de niveau recherche, publiés ou non, émanant des établissements d'enseignement et de recherche français ou étrangers, des laboratoires publics ou privés.

\section{(ㅇ)(1) $\$$}

Distributed under a Creative Commons Attribution - NonCommercial - NoDerivatives $\mid 4.0$ 


\title{
L'OCCUPATION PROTOHISTORIQUE DE LA GROTTE SUSPENDUE DE COLLIAS (Gard)
}

\author{
par A. COSTE, B. DEDET, X. GUTHERZ et M. PY
}

Effectuant une prospection systématique dans le canyon inférieur du Gardon, au cours de l'année 1971, deux d'entre nous' purent visiter un ensemble de cavités situées sur la rive gauche, à $1 \mathrm{~km}$ environ en amont rlu village de Collias (fig. 1). Bien que de dimensions modestes et d'accès malaisé, ces cavités ont été occupées à plusicurs reprises depuis le Néolithique jusqu'au Haut Moyen Âge. Si la plupart d'entre elles avaient reçu la visite d'archéologues régionaux - dont les plus célèbres furent sans aucun doute Félix Mazauric, puis l'abbé Bayol la Grolle Suspendue, par contre, était restée vierge depuis son abandon par les derniers occupants.

La situation de la grotte dans une zone très fréquentée des gorges du Gardon et l'éventualité d'un aménagement touristique de cette région imposaient une fouille de sauvetage, qui fut conduite en deux campagnes au cours des années 1971 et 1972. Différents horizons culturels, correspondant à trois phases bien distinctes de l'occupation de la cavité, furent ainsi mis en évidener au cours de la fouille. La première phase se rapporte au Chalcolithique.

L'occupation la plus importante se rapporte au Premier İge du Fer et fait l'objet de cette étude, que l'on complétera par des points de comparaison dans les gorges du Gardon et, au-delà, en Languedoc oriental. Dans ce but, une révision des collections de protohistoire issues de récoltes anciennes faites dans le canyon et conservées au Musée d'histoire naturelle de Nîmes nous a paru nécessaire².

Enfin, on a recueilli dans la Grotte Suspendue quelques vestiges d'une réoccupation all Bass-Empire.

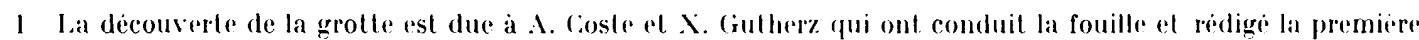

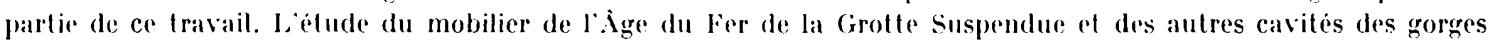
du ciardon est due a I3. Dedet et II. Py.

2 Nous remercions c. Coste, J. Pey, C. Roche et J.-L. Roudil pour leur aide sur le terrain, M. Raulet qui a réalisé les photos de la fouille, . I. le birecteur des antiquites historiques de langurdoc qui a bien voulu nous fournir l'autorisation nécessaire, et 11 . el .1 me Jeanlet qui nous ont ouvert les collections du Musée distoire naturelle de Nìmes. 


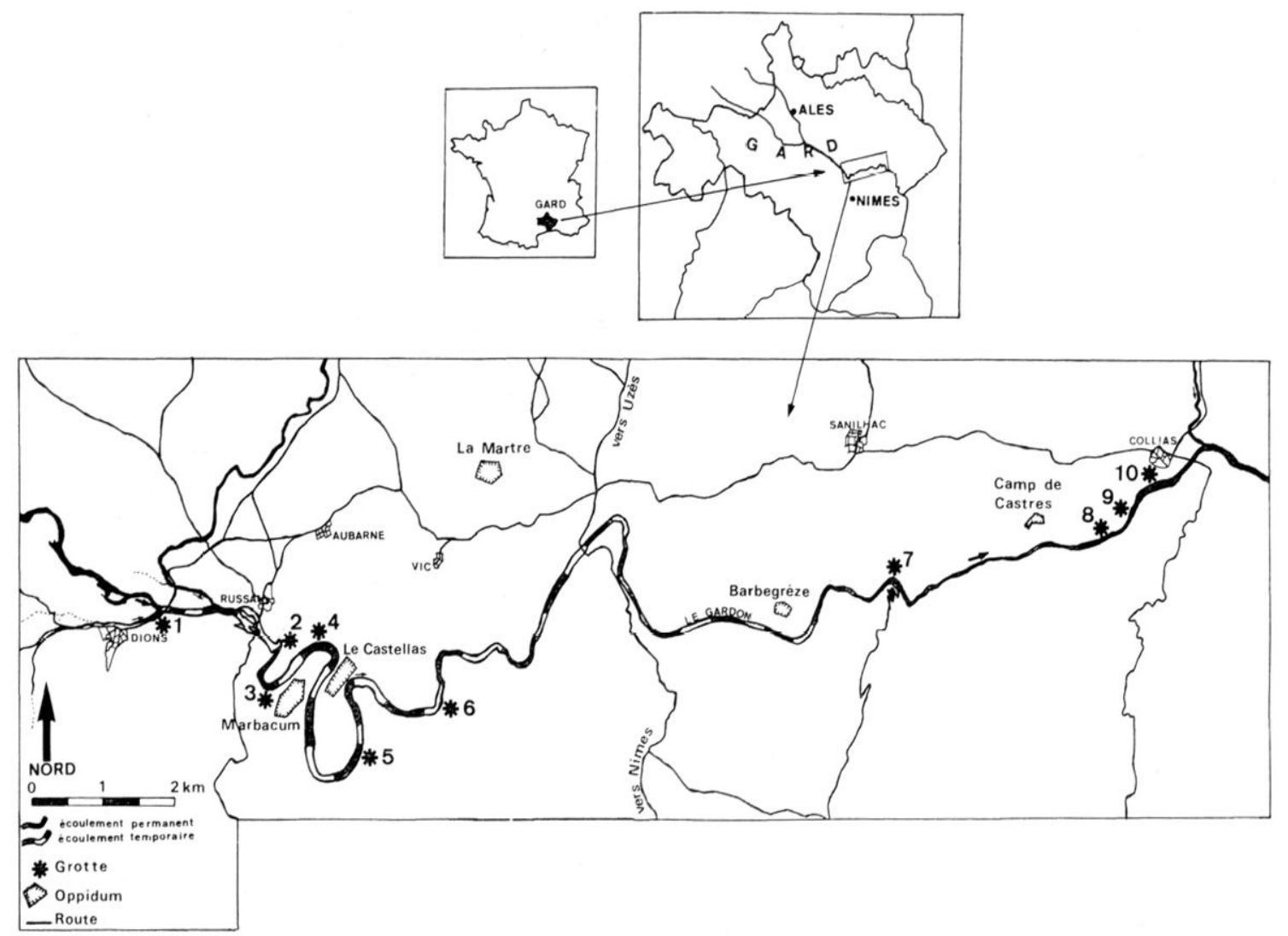

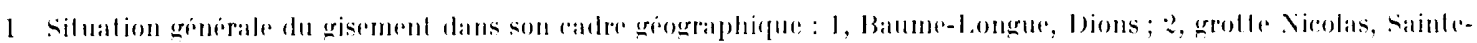

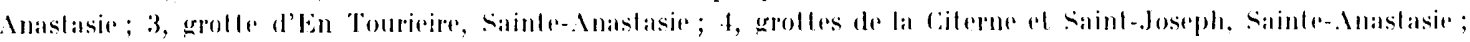

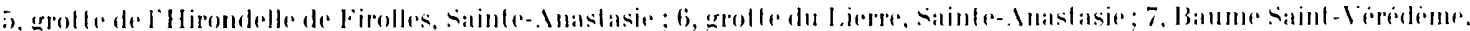

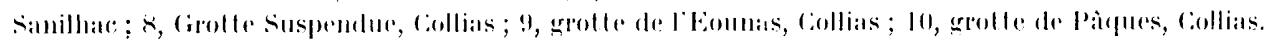

\section{LAS DONXISLS DE LA FOCILLE:}

La Cirotte Suspendue, dénommée ainsi en raison de sal situation all rentre d'une paroi verticale, s'ourre dans une barre de falaise, a mi-hauleur du versint nord des grorges, et domine le Ciardon de $40 \mathrm{~m}$ environ (fig. :2). Son antrée est masquée par un bouquet de chênes; on $y$ acecede en progressant sur une petite rive, puis an traversant une dalle de calcaire bombée.

La cavite se développe dans les calcaires compacts du Barremien inférieur a faciès Lrgonien (calcaire à rudistes). Il s'agit en fait d'une gallerie faisant partie d'un vaste complexe karstique, ayant vaisemblablement fonctionne comme perte, al dont les differentes branches se trourent actuellement morcelés par l'érosion. Certe grotte est formée par une galerie présentant un léger pendage vers l'intérieur at une section elliptique, de $4 \mathrm{~m}$ de large et de $2 \mathrm{~m}$ de haut. Le porche a ele remodelé par la desquamation d'origine revorlastique de la roche. La galerie n'est pénétrable que sur 12) m. calr all-dela, lat vonte s'affaisse brutalement jusqu'au niveau du remplissage.

La morphologie de la ravité nous a amené à considerer trois zones (fig. 3) : la zone antérieure, ou zone du porche, qui n’a pas été foullée car elle est occupée par un important 


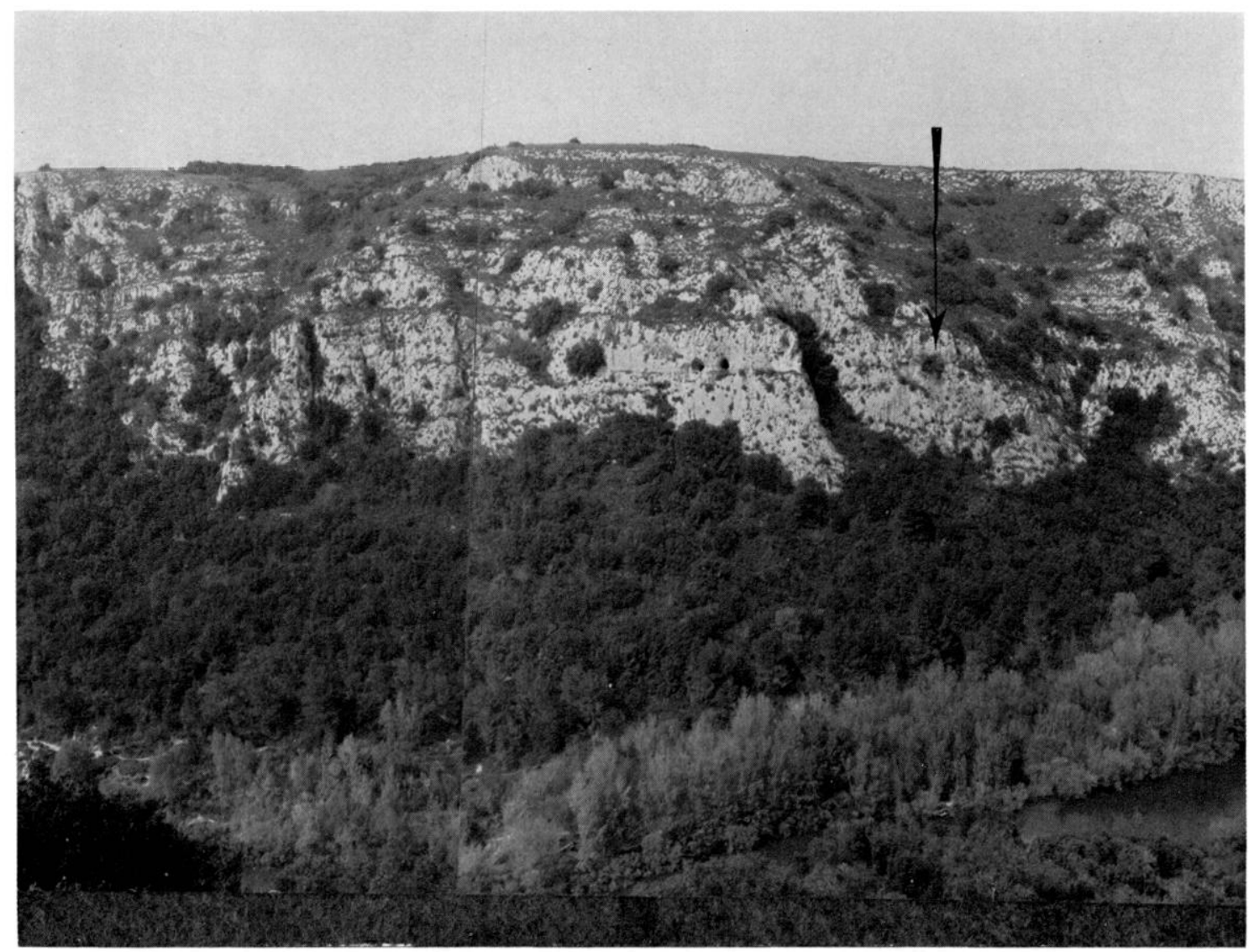

2 Ia Grolte suspendue vue de la rive droite des gorges du Gardon. J a grotte est indiquée par une fliche. On distingue nettement sur la gauche les derux ouvertures des grottes jumelles fouillees par li. Mazauric qui ont livere un abondaut mobiliere de l'. Ige du Bronze.

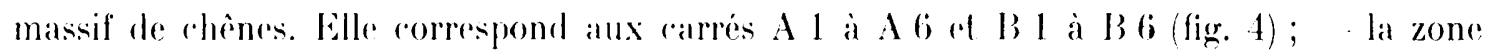
médiane (carrés (i, D), L. F, (i et II) où le substralum affleure sur presque toute la surface disponible, sauf contre la paroi ouest où a ete aménagée une fosse; la zone du fond (carrés I, J, K el I.) qui correspond à une dépression naturelle consécutive à un plongement des strates urgoniennes.

\section{Données straligraphiquers.}

Nous arons distingue deux ensembles sédimentologiques:

Les sédiments anciens : ils so limitent à quelques lambeaux d'une vieille brèche placueses contre la paroi par places, aree de menus restes de faune, et aux argiles rouges le base, vaisemblablement wïrmiennes. sur lesquelles reposent les niveaux archéologiques.

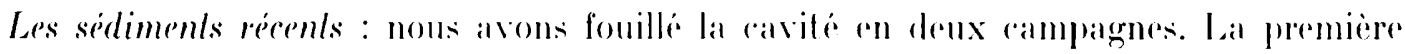
concernait la zone médiane at la serende la zone du fond. lans ces deux zones, la stratigraphie des sédiments récents présentait des différences notables; c'est pourquoi nous les décrirons séparément. 


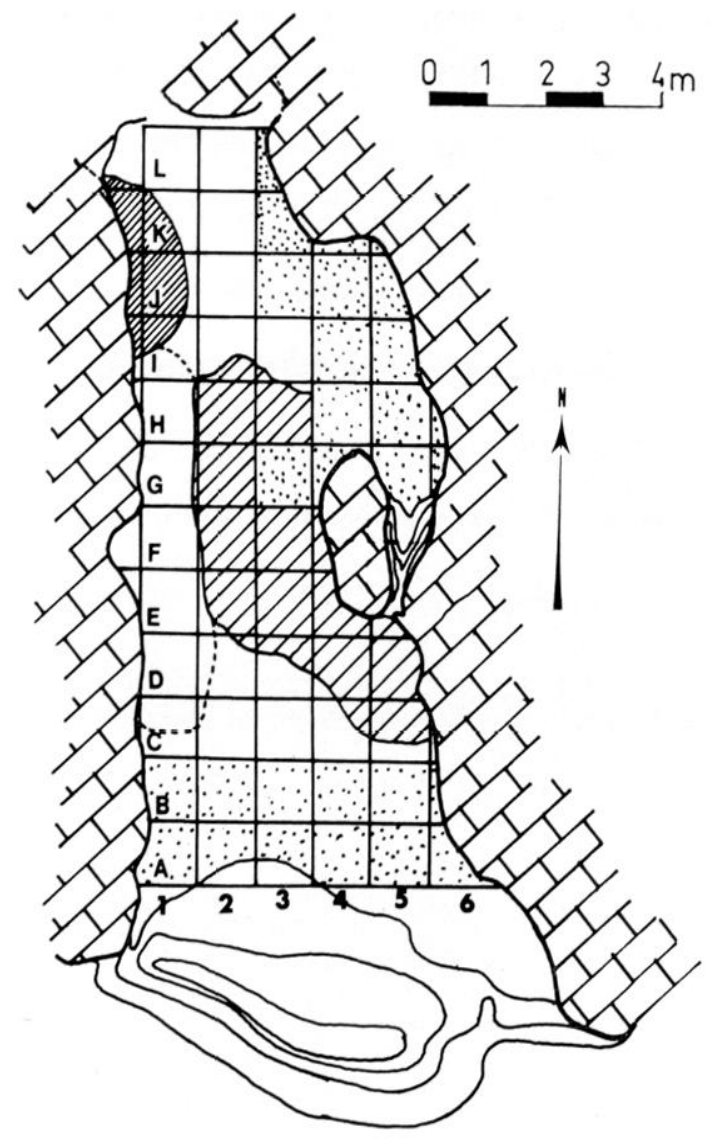

3 Pan de la Grotte suspendue avec matrialisation du carroyage en $\mathrm{m}^{2}$. En pointilles, zones non fouillées; en hachures larges, aflleurement labulaire du substralum urgonien ; rn hachures serrées, encroùtement stalagrmitique; en tiretes, contours de la fosse.

La zone médiane comprend les carrés ( $1-3$, I) $1-3$, E 1-3, F $1-2$, (; $1-2$ et H $1-2$. sur celte surface, on pouvait lire la straligraphie suivante, de hatul en bas :

couche 1 : encroûtement stalagmilique au pied de la paroi dans la \%one I) ந. Puissance : 4 i 5) ('m :

couche 2 a : poussierres éoliennes. I'une épaisseur de $20 \mathrm{~cm}$. cette couche stérile en matériel archéologique scelle le gisement sur toute sa surface et donne au sol son aspect rigoureusement plan;

couche $2 b$ : mince filet argileux et rougre. éparis en moyenne de $5 \mathrm{~cm}$; il contient quelques tessons gallo-romains, protolistoriques et chalcolithiques. Cette couche est le produit d'un remaniement. Elle n'existe que sur une surface restreinte, à l'extrémité sud de la fosse;

couche 3 : terre brune sur une épaisseur de $50 \mathrm{~cm}$ en moyenne, la couche 3 n'existe que le long de la paroi ouest où elle comble une forse de $1,50 \mathrm{~m}$ de large et de $6 \mathrm{~m}$ de long. Lille a donné un abondant mobilier du Premier İge du Fer. A la partie inférieure étaient concentrés les fragments de vase les plus importants;

couche $4 a$ : sommet des argiles rouges contenant quelques tessons chalcolithiques de type fontbouisse, sur une épaisseur de $10 \mathrm{~cm}$ environ;

couche $4 b$ : argiles rouges ou brunes du (guaternaire récent. avec quelques vestiges de faune.

La caractéristique essentielle de la morphologie de la zone médiane est l'affleurement du substralum rocheux en une plate-forme presque horizontale venant se raccorder avec le sommet du remplissage. Le long de la paroi ouest, une dépression, large de 1,50 m en moyenne, et qui correspond 


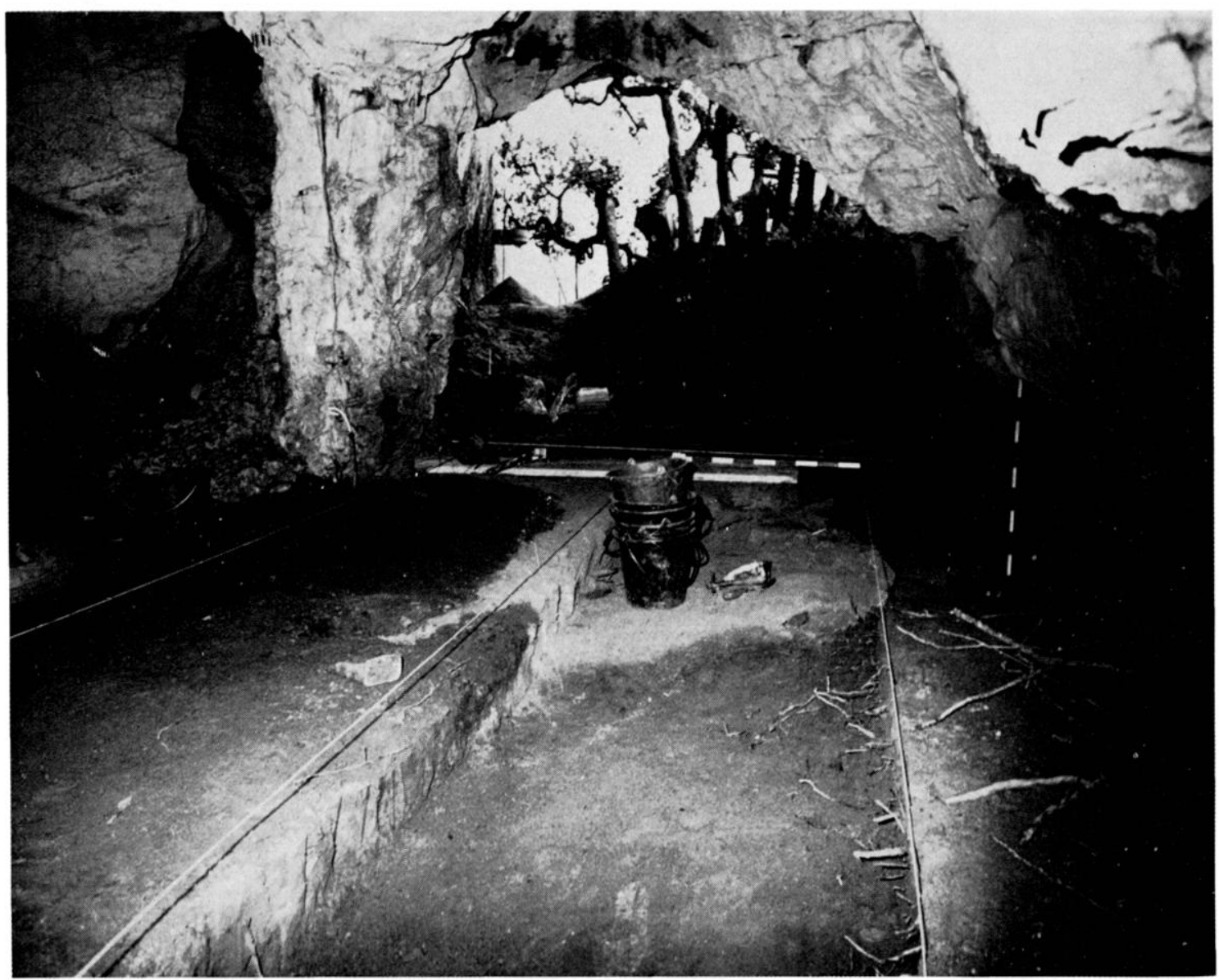

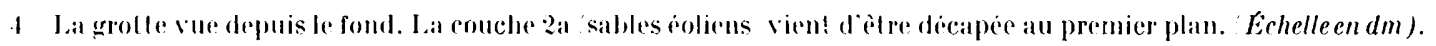

au chenal d'écoulement des eaux de pluie, a tronqué la plate-forme. Ge chenal nalurel est rempli par les arqiles quaternaires. Au cours de l'occupation rhalcolithique. les habilants abandonnent une partie de leur mobilier sur le sol de la cavilé, et la dépression joue alors le ròle de piegre nalurel. Cette phase correspond a la couche 4 a.

Lorsque les hommes de l'İge du Fer occupent à leur tour la cavité, ils aménagenl cetle rigole naturelle. Tne partie des déblais consécutifs à ce creusement sont rejetés sur l'affleurement du substratum. Ia répartition du mobilier chalcolithique sur la bordure de la dépression montre que le chenal primitif a été agrandi et régularisé sur toute la surface laissée disponible par le subslralum. L'hypothese d'un aménagrement du chenal en tranchée est confirmée par le profil abrupt du bord qui atteste un creusement anthropique. Cette Iranchée tronque la couche 4 a dont on ne retrouve que quelques lambeaux en place. localisés sur le pourlour.

Outre cet aménagement particulier, l'occupation du Premier İge du Fer est marquée par labandon d'un tres abondant mobilier, essentiellement de la céramique. Lónsemble de la cavilé est concernee par cette oceupation (couche 3).

Au Bas-Empire, une dernitre occupation a pour conséquence de moditier l'etal des lieux. En effet, il semble que ces derniers occupants aient nivelé la cavité, peut-ilre pour y installer un plancher comme pourrait l'altester la présence de clous. La fosse de l'Âre du Fer a ćté alors colmalée. aver les sediments disponibles sur plare qui contiennent du mobilier de l'İge du Fer, des vestiges chalcolithiques et des céramiques gallo-romaines fardives. L'aflleurement uronien est alors mis a nu el sa surface se racoorde parfaitement avec le sommet de la tranchée qui a été comblée. 


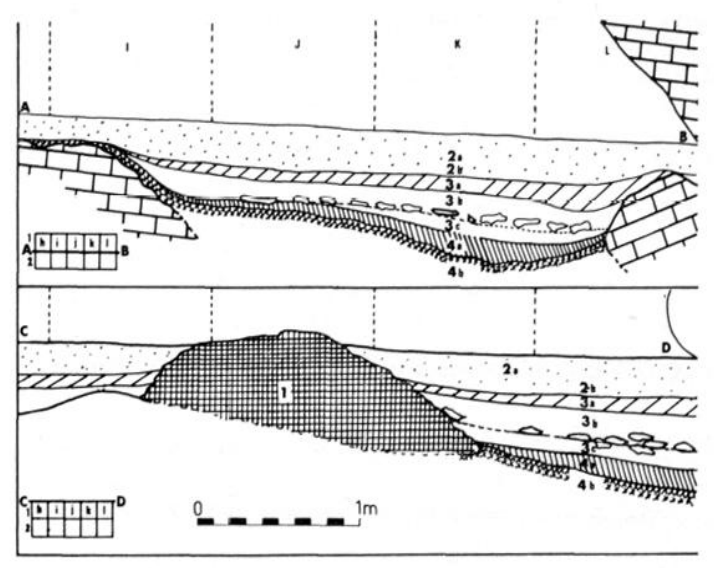

5) Coupes strat igraphiques de la zone du fond. En haul, selon A-13; en bas, selon (-I); I, J, K, L : projection du carrogage donnant l'échelle; 1 , encroutement stalagmiligque; 2:1 : poussieres ioliennes; : 2h : humus; 3a : couclie d'argile rouge ; 3he al c: : terre humicyur moiratere, legerement charbonneuse aver niveau de cailloux calcaires a la base; fa : argiles rouges ; flb: arogiles qualernaires sondies sur $50 \mathrm{~cm}$ de profondeur.

La slraligraphie de la zone médiane prend alors l'aspect que nous lui connaissons; une derniere rouche de poussiére éolienne provenant des limons du Gardon soulevés par les rafiles de vent, se mel progressivement en place. Localement, au niveau des ócoultoirs, se forme un encroùtement slalagmilique.

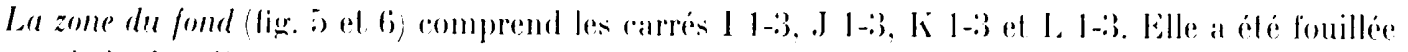
au cours de la deuxieme campagne. L'exploralion de celle partie de la grofle répondant a un double besoin. l'une part compléter le mobilier provenant de la zone médiane, d'autre part confronter

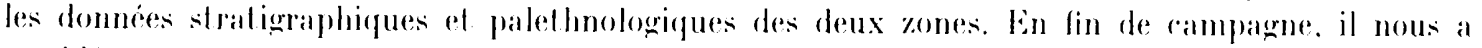
semble que la poursuile des travaux napporterail pas de donnee susceptible d'erdarer diun jour nouveau les problimes posis. C'est pourquoi une zone de $6 \mathrm{~m}^{2}$ a éte laissé comme lémoin lig. : 3$)$.

la stratigraphie de la zone du fond comprend de haut en bas :

comche 1 : encroùtement stalagmilique. plus dense que dans la zone médiane. Au niveau des carres o 1 et 1 , il se forme un veribable massif de 0,50 m d'épaiseur, venant s'appuyer directement. sur les argiles de base;

conche 2 : celte couche a elé subdivisée en deux niveaux :

niceau $2 a$ : poussieres éoliennes stériles en mobilier archéologique, de 20 am de puissance en moyenne.

niveau $2 b$ : humus brun de $10 \mathrm{~cm}$ d'épaisseur, aver lessons de céramique gallo-romaine tardive;

couche 3 : elle est subdivisée en trois niveaux :

nivean $3 a$ : sédiment argileux rouge sombre, de 10 em d'épaisseur en moyemne, sépaisisisant. régulierement vers le fond. Mobilier protohistorique el céramique tournée gallo-romaine. Ce niveau correspond à la couche 2 a de la zone médiane.

nivean 3 b : lerre humique, noiratre, avec quelques charbons de bois, épaisse en moyenne de :30 cm. Le niveau 3 b s'amincit régulierement dans la zone I. I sa base, on note une forte concentralion de pierres calcaires anguleuses. formant un niveau régulier. Le désordre el le chevauchement de rertaines pierres prouvent qu'il ne s'agit pas d'un dallage. Parmi ces pierres. on note la presence d'une meule en molasse, d'un broyeur el d'un tris abondant mobilier du Premier İe du Fer. Ce niveau correspond à la couche 3 de la zone médiane. G'est la que sont concentrés les restes de faune.

niveau $3 c$ : silué sous te lit de cailloux. il est constilué d'un sédiment terreux el noiraitre. comparable à celui du niveau précédent. Mis a part l'apport de blocs séparant les deux niveaux, il n'y a pas de rupture sédimentologique. Le mobilier est composé de céramique du Premier İge du Fer, quelques tessons du Bronze final II et quelques lémoins chalcolithiques. 


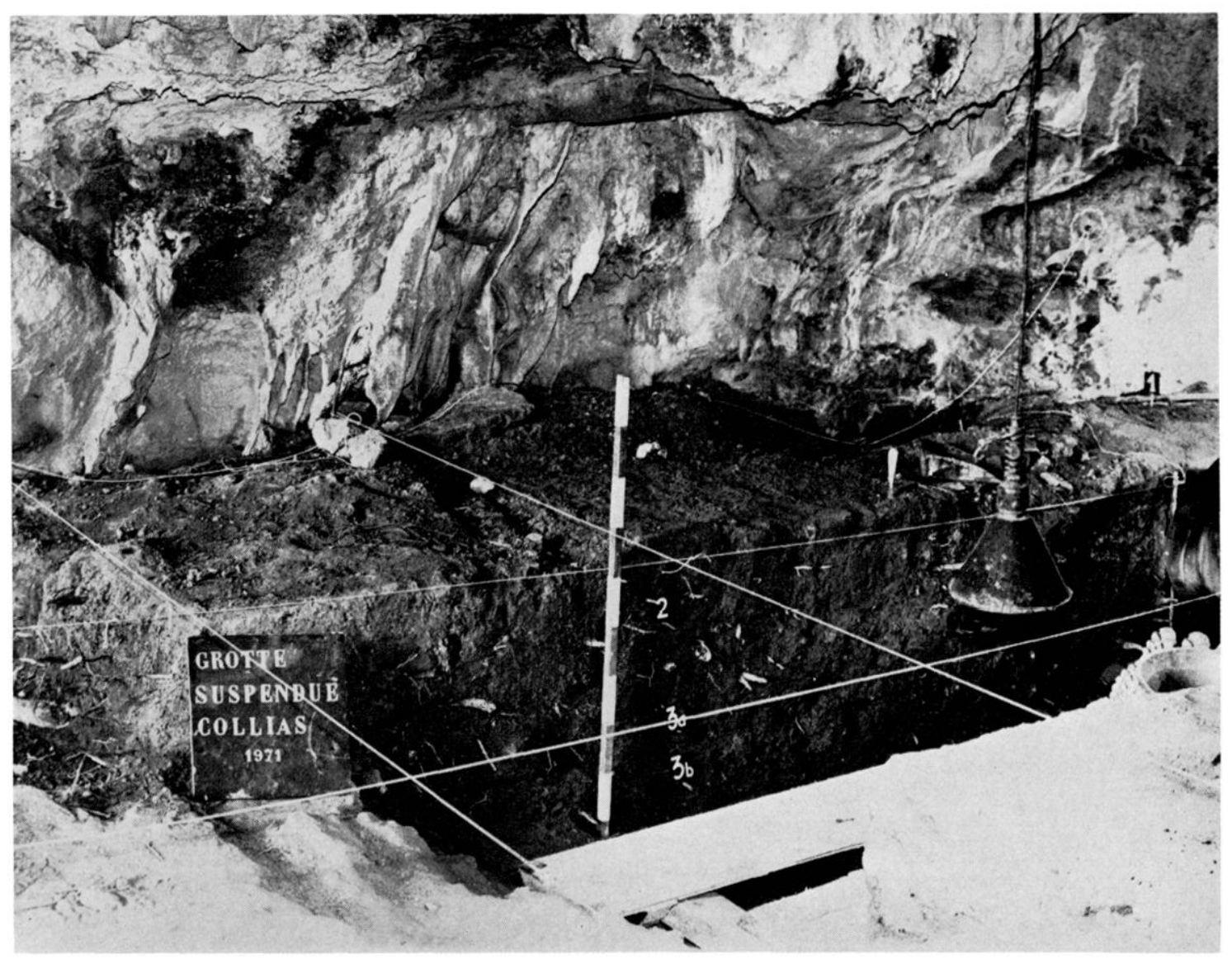

fi Stratigraphie de la zone du fond. Vue prise apres decapage de la couche 2a contre la paroi ouest. (Lichelle en dm).

conche $t$ : niveau $t a$ : argile rouge localement encroùlée d'une puissance de $10 \mathrm{~cm}$ en moyenne et s'épaississant progressivement vers le fond. Ce niveau a donné une céramique a cordons impressionnés au doigt ainsi que des éléments de céramique fontbuxienne. Cine aline losangique en bronze permet de le définir comme un horizon de Iransition Cihalcolithique-Bronze ancien.

nibean $+b$ : argiles rouges encroùtées el archélogiquement stériles.

Les aractéristiques morphologiques de celle zone de la cavilé difrirent de celles de la zone médiane el bien que. dans ses grandes lignes, la straligraphie soit idenlique. des éléments nouveaux apparaissent.

Dans la zone médiane. le substralum a une allure presque horizonlale sur la majeure partie de la galerie, a l'exception du chenal d'écoulement des eaux aménagé en fosse. lons la zone du fond. il en va autrement a partir des rarrés I. le substratum s'abaisise rapidement suivant une pente de 150 environ. Celte inclinaison, conforme a la structure encaissante, a pour eflet principal de ménager une dépresssion en contrebas de la zone médiane et pour conséquence secondaire de donner à la couverture sidimentologique son allure en biseau. avec couches transoressives. Comme pour la fosse de la zone médiane, cette dépression a fonctionné comme pieco a sédiments et a mobilier. Ceci est d'ailleurs altesté par l'élalement des lessons sur les pentes de la dépression, selon un pendage conforme a celui des couches. Mais alors que dans la zone médiane il y a eu aménagrement anthropique. dans la zone du fond la dépression est entierement naturelle.

En ce qui concerne l'occupation chalcolithique. la zone du fond amene de nouvelles données : si dans la zone médiane, la couche de cette époque était sérieusement Ironquée par les remaniements 


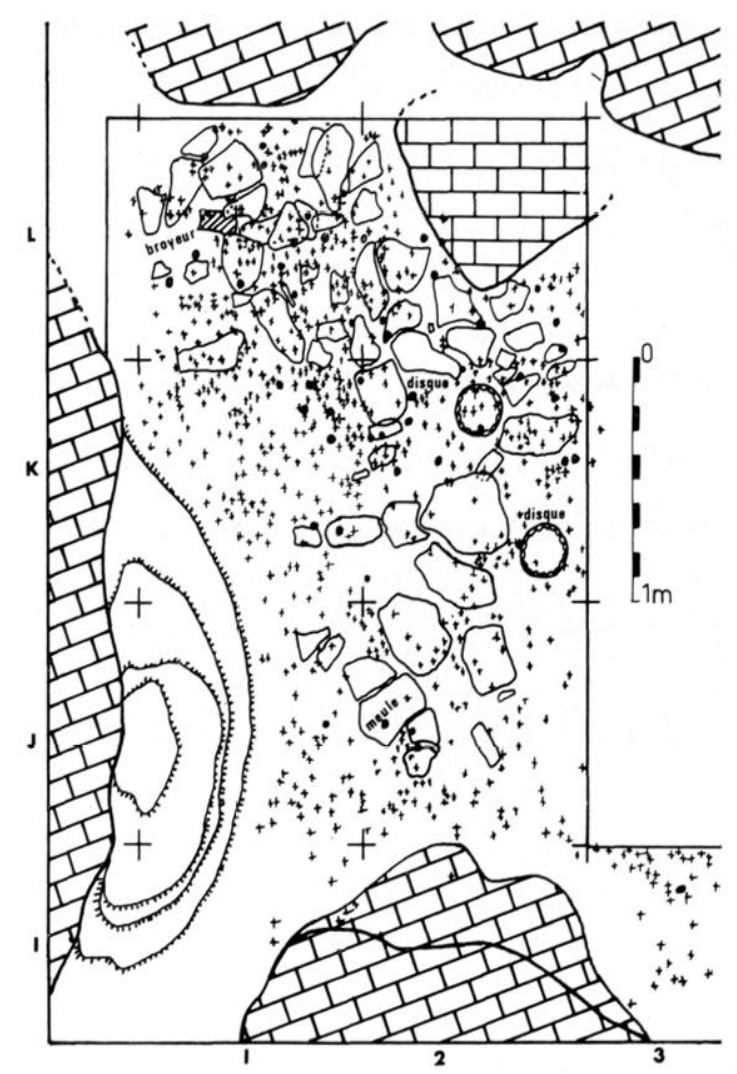

7 Repartition du mobilier probohistorique dans la zone du fond : croix tessons; points faune. Noter la présence an niveaulu des caillonx d'une meule of d'une molette, ainsi que de deux disques an calcaire courereles de vases:

postérieurs. la zone du fond. elle, est restée en place. Ceci vient d'ailleurs confirmer l'hypolhise du creusement de la fosse de la zone médiane.

La couche :3 c qui surmonte ce niveau chalcolithique est également bien en place. Eille correspond au sol d'occupation initial de Premier İge du Fer. Śa relative pauvreté en mobilier peul s'expliquer par le fait qu'il s'agit d'une zone humide. mal érlairée el arcidentée. Chronologiquement. re niveau doit atre mis en relation aver la base de la couche 3 de la \%one médiane.

Les cailloux de la base de la couche 3 b et la couche 3 belle-meme correspondent a un rejet de sédiment el de mobilier par les occupants. Lin effel. en plus du fait qu'une meule et un broyeur se trouvent mìlés aux cailloux, vient s'ajouter le racrordement de lessons provenant de la zone médiane aver d'autres venant du fond (fig. 7 ).

Les couches 3 a et 2 b sont altribuables a l'occupation gallo-romaine Lardive, qui. dans rette zone aussi, at remanié les niveaux plus anciens, mais avec moins d'ampleur. La couche 2 a vient normalement sceller le remplissage, comme dans la zone médiane.

L'observation de la morphologie du fond de la galerie nous a amené à sonder la zone ou le remplissage vient buler contre la voûte surbaissée. La ravilé ne se termine en effet pas là, mais se poursuit par un réseau actuellement inaccessible. Il nous importait donc de savoir si les orcupants du Premier ige du Fer, et a plus forte raison ceux du Chalcolithique, avaient utilisé la zone située au-dela de ce point bas du plafond. La désobstruction a bulé sur un remplissage forlement concrélionné; la voûte continue à s'abaisser de telle sorte que mème au Chalcolithique, le passige était pratiquement inutilisable. La zone siluée au-dela de cet obstacle est donc à coup sùr stérile au point de rue archéologique, seule la couche à faune quaternaire se prolongeant au-deli. 


\section{Chronologie de l'occupation de la grolle.}

La stratigraphie de la Grotte Suspendue, compliquée par les remaniements successifs dus aux différentes occupations, ne nous a pas permis de saisir toutes les morlalités d'aménagement de la grolte. Nous en résumerons seulement les différentes phasses.

Au Chalcolithique, un habitat relativement modeste et peut-être de courte duré affecte toute la surface disponible. Les vases sont cassés et dispersés et il n'est resté du moins dans la zone foullée, aucune trace de foyer ni d'aménagement particulier.

Au Bronze final II, une occupation très épisodique est marquée par la présence de quelques tessons, appartenant à jo ou 6 vases au maximum, et de quelques éléments de parure : bracelet en jais et perle spiralée en bronze. Ce mobilier se trouve soit à la surface de la couche chalcolithique (couche 4 a), soit dans la couche 3 b de la zone du fond. La grotte ne semble pas avoir constitué alors un habitat fixe, mais plutot un abri temporaire et accidentel.

Au début de l'Âge du Fer, la cavite est à nouveau occupée, selon des modalités que l'étude du mobilier s'efforcera ci-après de définir, puisque la stratioraphie et la répartition des rases ne permettent pas de les préciser dès l'abord.

Enfin, la dernière occupation de la Grotte Suspendue, au Bass-Empire, correspond à un processus connu par ailleurs ${ }^{3}$.

\section{Données ethnographiques.}

Si dans le domaine chronologique des incertitudes demeurent, il en est de mème pour l'interprétation des structures découvertes dans la cavité. Én effet, bien que nous n'ayons pas à revenir sur l'existence d'une fosse creusée au Premier $\hat{A} g e$ du Fer, il faut cependant s'interroger sur la fonction d'une telle structure. On peut constater que les vases ont été déposés aussi bien dans cette fosse que sur la plate-forme qui la borde. On notera également que la fosse ne se termine pas brutalement, mais qu'elle s'atténue progressivement dans la zone I 1. Elle ne contient pas de restes de faune, ni de charbons de bois, alors que le fond en a donné une certaine quantité. (On peut expliquer cette alsence par le fait que la zone favorable à l'etablissement de foyers est celle du porche, aujourd'hui occupée par un massif de chênes. Le fond de la grotte semble avoir reçu les déchets provenant de la zone d'activité domestique : céramiques cassées, restes de repas carnés, pierres et meule mise au rebut au cours d'une phase de réorganisation de l'habitat.

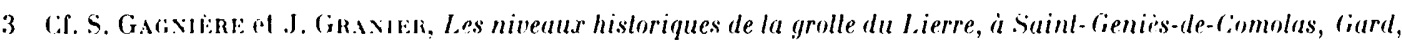

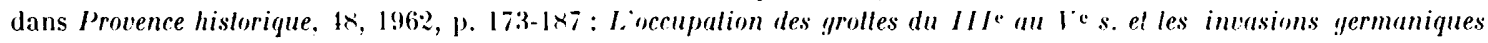
dans la basse vallée du Khòne, dans Prolence historique, 53, 1963, p. 295-239, citent, en particulier dans les gorges

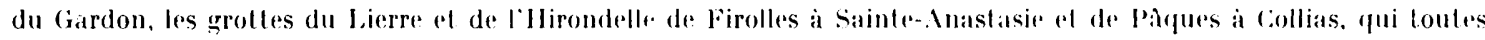

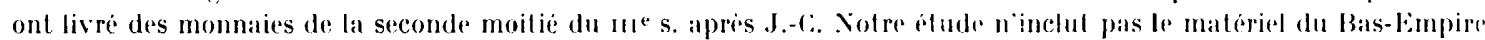

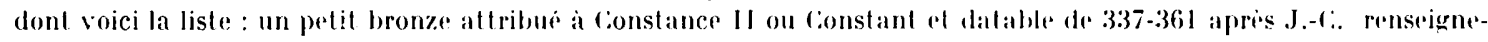
ments J.-.l. Lassere ; un vase caréne en céramique sigrllé grise estampée, de forme higoir le proche de J. Racorn, Sigillé paléochrétienne grise el orangre, dans fiallia, XXVI, I96, p. 229, pl. XVI, vase Narbonne 1.1 ; partie superieture d'une olla à decor imprimé a la roulette; 38 bords moulures d'ollae ; 7 fonds plats ; 2 bords de jalles ; plusieurs fracements d'un vase fermé en sigillé claire 13 ; des fragments de vases en verre, dont un bord; une fusaïole en os et plusienrs fragments de fer, dont quelipues clous. 


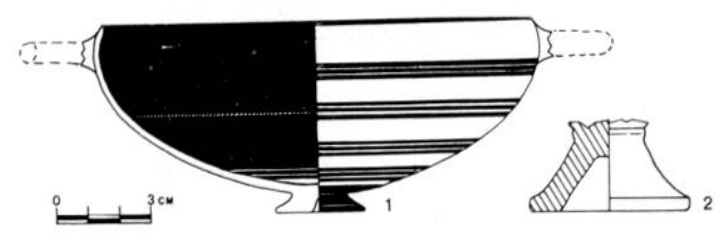

8 l, skyphos de style rhodien; 2, pied de coupe psendo-ionienne.

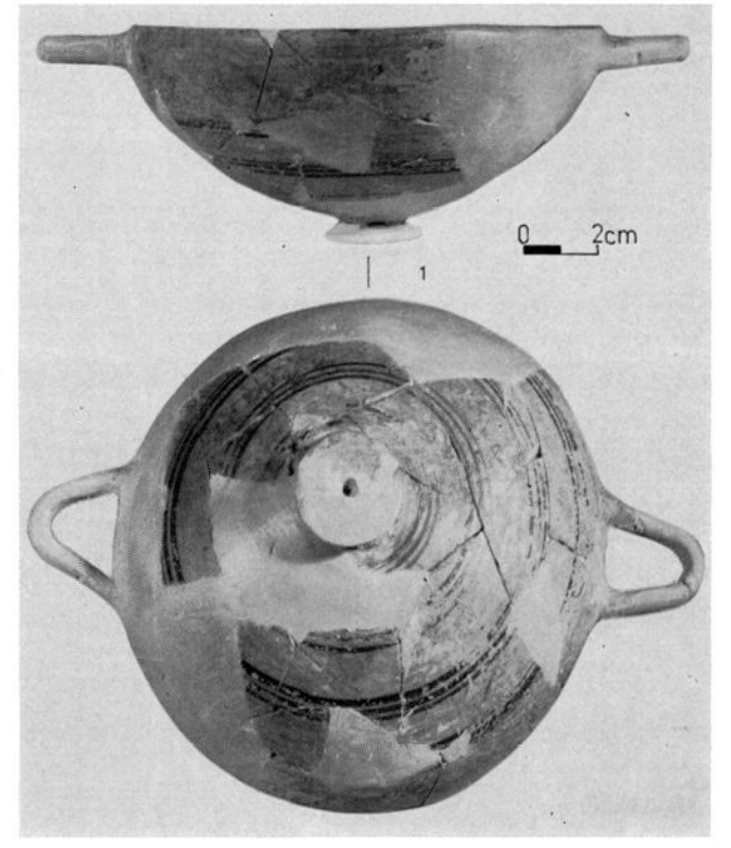

Ce qui permet d'éarter l'hypothese de l'utilisation de la fosse comme dépotoir, céest done précisément que le fond de la grotte semble avoir répondu a cette fonction. Dans ce cas, le rôle de la fosse de la zone médiane reste indéterminé. Nous verrons que l'analyso du mobilier céramique qu'elle a livré orientera nos hypothèses de préférence vers un dépôt d'objets dans une dépression qui, lors de l'oceupation protohistorique, resta probablement vide ou servit de remise.

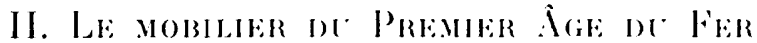

Le mobilier du Premier îge du Fer trouré dans la Grotte Suspendue est composé de 4 lots d'importance tres inegale : tout d'abord quelques vases d'importation en céramique tournée; ensuite le groupe tres aloondant des vases non tournés ; enfin, deux séries d'objets beaucoup moins représentes : Jes mobiliers lithique et métallique. Dans un premier temps, nous ferons l'inventaire analytique de ces documents; ensuite en mettant an relation les données de la fouille, la répartition des tessons, leur degré de fragmentation et les enseignements de la typologre ef de la chronologie des differents objets. nous essaierons de comprendre les modalités de l'occupation protohistorique de la grotte.

\section{Círamigte gregque orikntale}

Shyphos de slyle rhodien (fig. $8 . \mathrm{n}^{0} \mathrm{I}$ ); inv. (is 184. Piece fragmentée, mais reconstituable, à l'exception des anses ; vasque hémisphérique et profonde; bord rentrant à lèvre amincie; pied discoüdal bas à petite dépression circulaire et centrale; départ d'anses horizontales à section arrondie. Pâte jaune pâle, fine, dure. homogène et trìs cuite; dégraissant 
invisible à l'œil nu, si ce ne sont de rares impuretés; surface soigneusement lissée à l'extérieur et traces de tournage (stries dues au doigt) à l'intérieur, notamment sous le bord. Le vase est entièrement engobé : l'engobe, de couleur beige, est passé au pinceau, comme le montrent certaines superpositions à l'extérieur; il est fin, lisse et luisant. Sur l'engobe est peint le décor : à l'intérieur, la vasque est entièrement peinte en brun noir, sauf un disque de $3 \mathrm{~cm}$ de diamètre au fond, souligné sur sa bordure de deux filets peints. À l'intérieur encore, la vasque porte à mi-hauteur un filet de rehaut blanc appliqué sur la peinture. İ l'extérieur, le décor peint se compose de haut en bas d'un fin liseré sous la lèvre (débordement de la plage intéricure), puis de 4 groupes de 3 filets horizontaux et enfin d'une bande plus large au contact du pied.

\section{Céramique grecque d'Occident}

a) Un pied conique de coupe pseudo-ionienne de type $\mathrm{B} 2 \mathrm{de} \mathrm{G}$. Vallet et F. Villard (fig. 8, no 2); inv. GS 185; le pied a une base épaisse, son attache à la vasque est cylindrique et pleine, et présente un petit bourrelet en relief; pâte jaune beige, assez tendre, très micacée (fin mica doré et blanc), qui contient aussi des inclusions blanches et rouges qui font penser à une argile massaliète. Le pied est couvert à l'extérieur d'une peinture brun rouge peu résistante et en grande partic effacée.

b) Un pelit fragment de vasque de coupe pseudo-ionienne (inv. GS 187) ; pâte jaune beige bien cuite et lissée en surface, à dégraissant fin et moyen de mica blanc ; traces de peinture noire à l'extérieur et à l'intérieur.

c) Un fragment de vasque de coupe carénée en céramique grise monochrome d'Occident (inv. GS 186); pâte gris bleu, moyennement dure, micacée et comportant un très fin mica blanc. Peinture noire, mince et peu résistante à l'extérieur et à l'intérieur du vase. Légère rainure au-dessus de la carène douce à l'extérieur. Il s'agit d'une jatte carénée, probablement de la forme $11 \mathrm{~A}$ de F. Benoît ${ }^{5}$.

\section{Amphores massaliètes}

79 fragments appartiennent à plusieurs amphores massaliètes à pâte micacée. Deux tessons montrent qu'il s'agit d'un type à col assez haut et cylindrique, à panse sphérique et contact col-panse anguleux. Les pâtes sont en majorité jaunes et comportent du mica blanc et rose en écailles de poisson, et des inclusions rougeâtres caractéristiques de l'amphore de Marseille. Il s'agit d'amphores du type I de F. Benoît ${ }^{6}$.

\section{Céramique xon tournée}

Très fournie (260 vases au moins), la catégorie des vases non tournés peut être divisée en sept groupes :

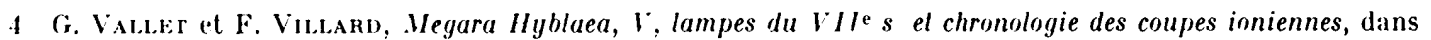
Mílanges de l'́cole francaise de Rome abrégé : MEFR, LXVII, 1955, p. 7.24, et notamment p. 27.

5 F. Bexo1t, Recherches sur l'hellénisalion du Midi de la Gaule, Aix-en-Provence, 1965, p. 161 et pl. $29, \mathrm{n}^{\circ} 1$.

6 Voir F. BExolT, op. cil., p. 184 et pl. 43 et 45. 

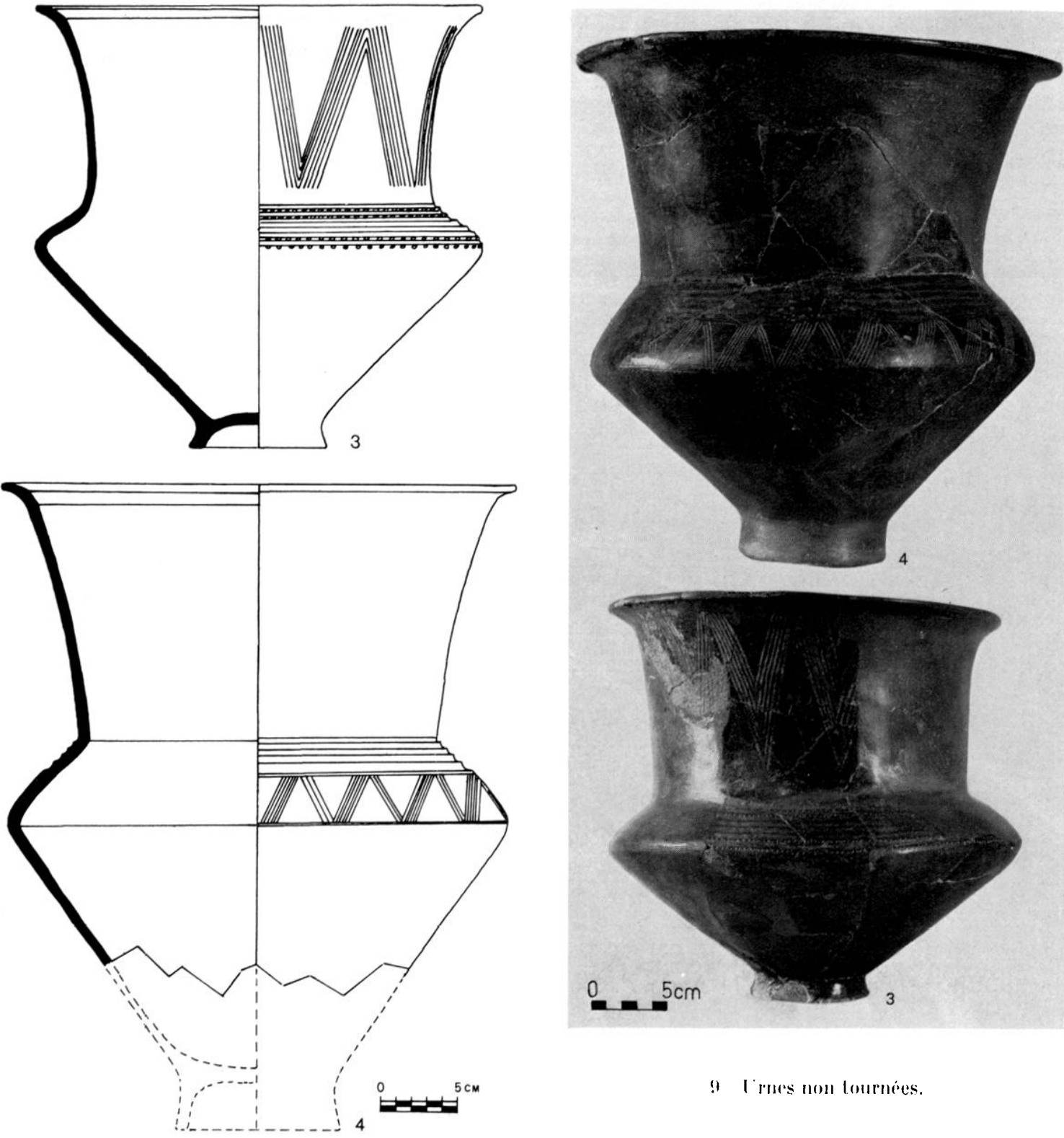

9 Irnes non lournées.

\section{Première série d'urnes.}

Ciette série regroupe les urnes qui possèdent un col très haut, généralement plus haut que la panse; une panse très galbée, parfois même carénée; et un fond qui est soit un pied bas divergent, soit un fond creux à talon. Ce groupe est fort de 333 exemplaires, ce qui représente $12,7 \%$ des vases non tournés et $28,4 \%$ des urnes. La forme complete est connue par deux exemplaires entiers et par quatre en grande partie conservés.

Fig. $9, n^{\circ} 3$ : vase complet (inv. (is 111 ) de forme $126 \lambda^{7}$. bord C 21 , fond 62 C. rapport 91.

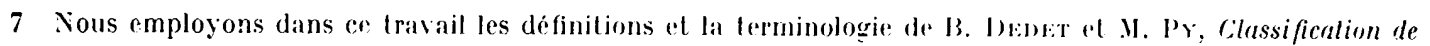
la céramique non tournée protohislorique du Languedoc méditerranien, suppl. 4 ì la kev. arch. de Narbonnaise, 1975. 
Décor : pour le col. ligne brisée de six cannelures fines I racées au brunissoir; pour l’épaule. sept cannelures plus larges et horizonlales. la deuxieme el la septieme en partant du haut étant encadrées par deux alignements d'impressions. Jégraisisant bien calibré de calcaire broyé el de mica. Aménagement des surfaces : extérieur no 1 , col el panse; intérieur $n^{0} 2^{8}$.

Fig. 9, no 4 : panse et col d'urne (inv. 46 et 92) de forme probable 126 . 1. dont le rapport devait avoisiner 115 . Bord $\mathrm{C} 21$. Le décor est situé sur l'épaule et se compose de cinq cannelures surmontant une ligne brisée (3) et 6 incisions fines alternées) entre deux doubles lignes horizontales. Dégraissant bien calibré de calcaire broyé ef de mica. Aménagement des surfaces : exlérieur no 1 . col et panse; intérieur no 2 .

Fig. 10. no 5 : panse el col d'urne (inv. (is 108 ) de forme probable $126 \mathrm{\lambda}$, dont le rapport avoisine 100. Bord C 21. Décor : rangée horizontale de petites impressions triangulaires située au sommet de l'épaule. Dégraissant bien calibré de calcaire broyé el de mica. Aménagement des surfaces : extérieur no 1 , col el panse (coups de polissoir visibles a la base de la panse); intérieur no 2.

Fig. 11, no 9 : panse el col d'urne (inv. 133) el 21:) de forme probablement semblable a celle des vases précédents. Iégraissant : calcaire broyé; quart\% et mica. mal calibré. Aménagement des surfaces : à l'extérieur, col el panse no 2 ; a l'intérieur, $n^{\circ} 2$.

Fig. 12, no 12 : col d'urne (inv. (x) 113); bord C 21 ; décor : sur le col, ligne brisée de 4 ou 5) cannelures fines el tracées au hrunissoir. Dégraissant bien calibré composé de calcaire el de calcite broyés el de mica. Aménagement des surfaces : à l'extérieur no 1 ; à l'intérieur no 2.

Fig. 12, no 13) : urne complite (inv. 43); forme 222 B; bord G 11; fond 22 3 présentant de très nettes traces d'usure. Rapport 102. Dégraissant bien calibré de calcaire broyé et de mica. Aménagement des surfaces : a l'extérieur no 2 , col et panse; à l'intérieur, altéré.

L'étude d'ensemble des formes complètes et des fragments qui s'y ajoutent, permet de définir comme suit les différents caractères des vases de cette série : les formes attestées sont 126 A et $222 \mathrm{I}$, la première étant de loin la mieux représentée. Les bords sont, dans l'ordre décroissant de fréquence : bord C: 11 (11 ex. : fig. 10, $\left.\mathrm{n}^{0} 8\right)$; bord C 21 (8 ex. : fig. 9, nos 3 et 4 , fig. $10, n^{0} 5$, fig. $11, n^{0} 10$ et fig. $\left.12, n^{0} 12\right)$; bord $\operatorname{col} 1\left(6\right.$ ex. : fig. $\left.10, n^{\circ} 6\right)$; bord BO 1 ( 1 ex. : fig. 10, no 7) ; enfin, bords 1311 et DO 4 (1 ex. de chaque). Deux fonds

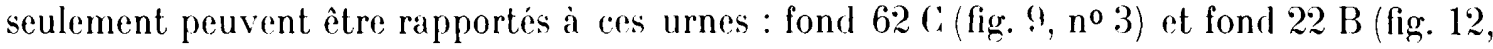
$\left.\mathrm{n}^{0} 13\right)$.

Les décors ornant certaines de ces urnes se trouvent dans un cas sur le col, dans un cas sur le col et l'épaule et dans quatre cas sur l'épaule. Il s'agit sur les cols de cannelures fines; et sur les épaules de cannelures fines, de cannelures larges, d'incisions fines et d'impressions. Dans ces différentes techniques, trois motifs seulement sont traités : les groupes de lignes brisées, les groupes de lignes horizontales et les rangées horizontales d'impressions triangulaires, circulaires ou fusiformes (fig. 9 à 12 et fig. $16, n^{\text {os }} 22$ et 44).

Nous avons noté trois catégories de dégraissant, tous à base de calcaire ct de mica : calcaire et mica : 19 ex. $(58 \%) ; \cdots-$ calcaire, calcite et mica : 9 ex. $(27 \%) ;-\cdots$ calcaire, quartz et mica : jox. $(15 \%)$.

Les inclusions de calcaire et de calcite sont broyées ; le quartz est roulé. Par ailleurs, dans 10 cas, le dégraissant est bien calibré et dans 22 cas, il est mal calibré. La surface 


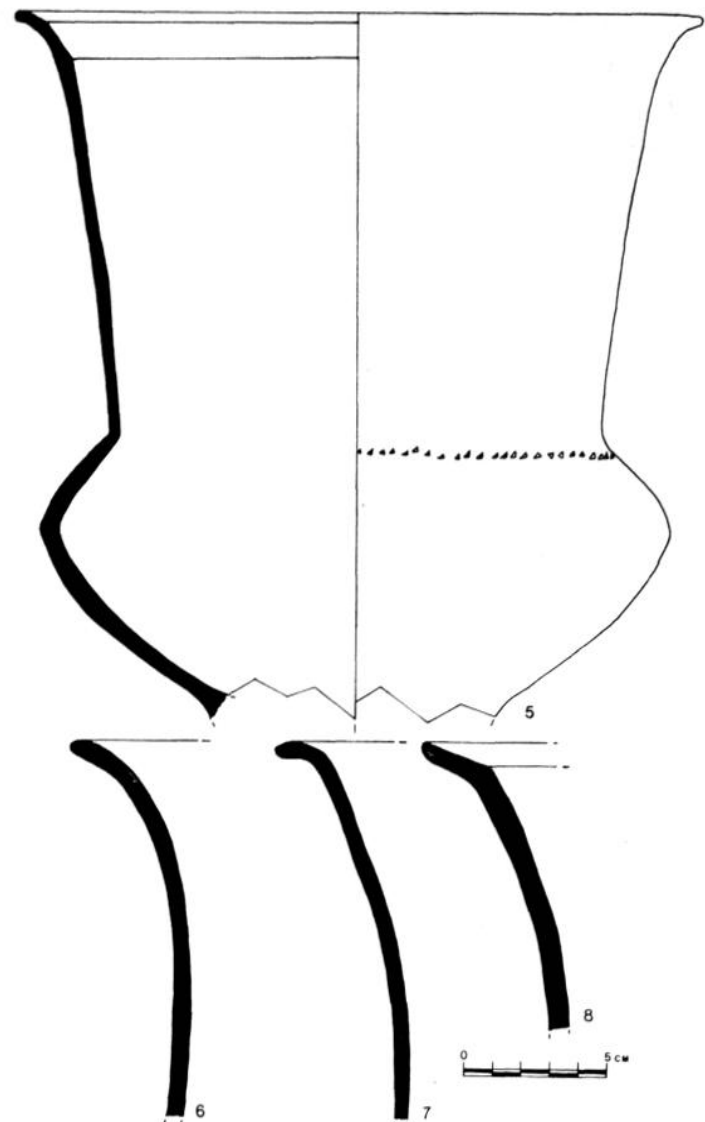

10 Urnes non tournées.

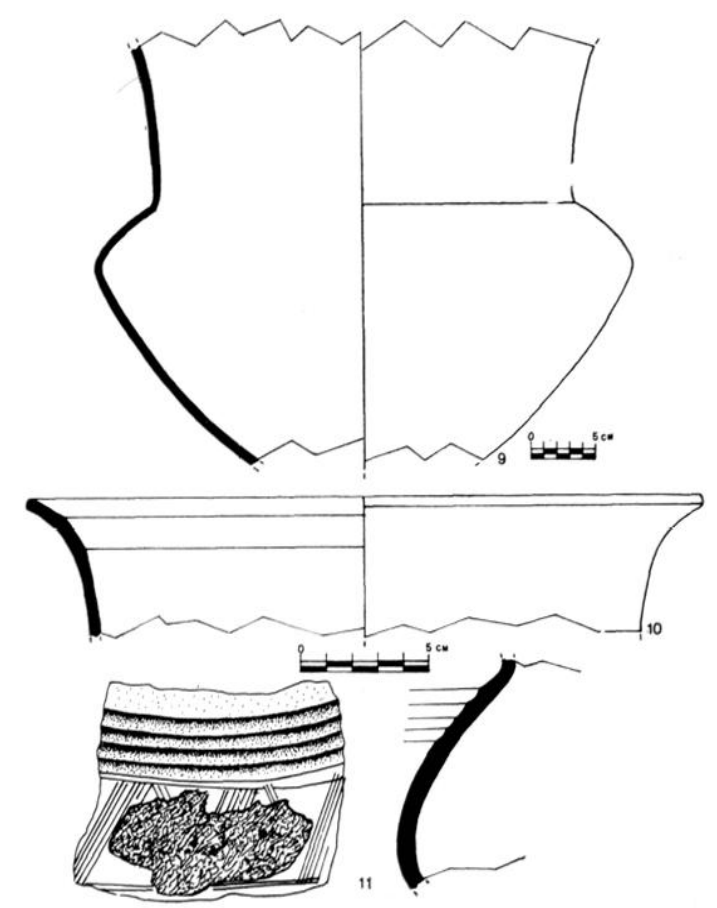

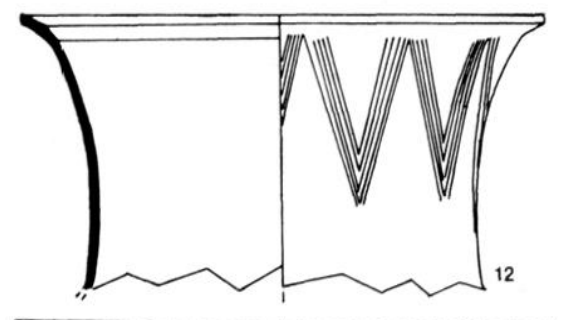

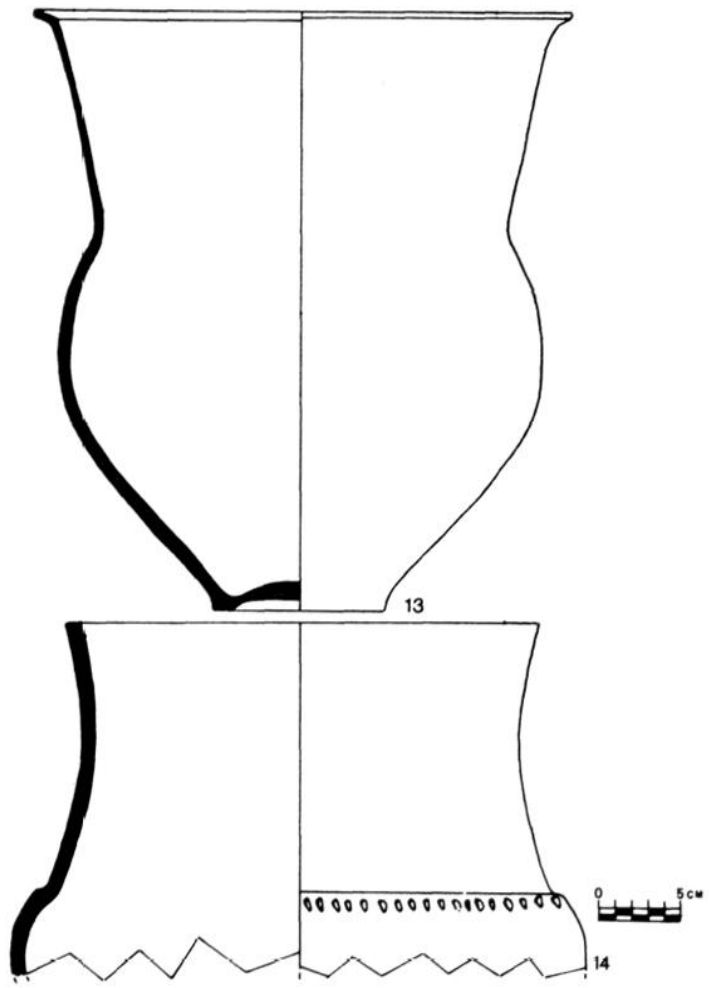

12 Urnes non tournées.

«- $11 \quad$ Irnes non tournées. 

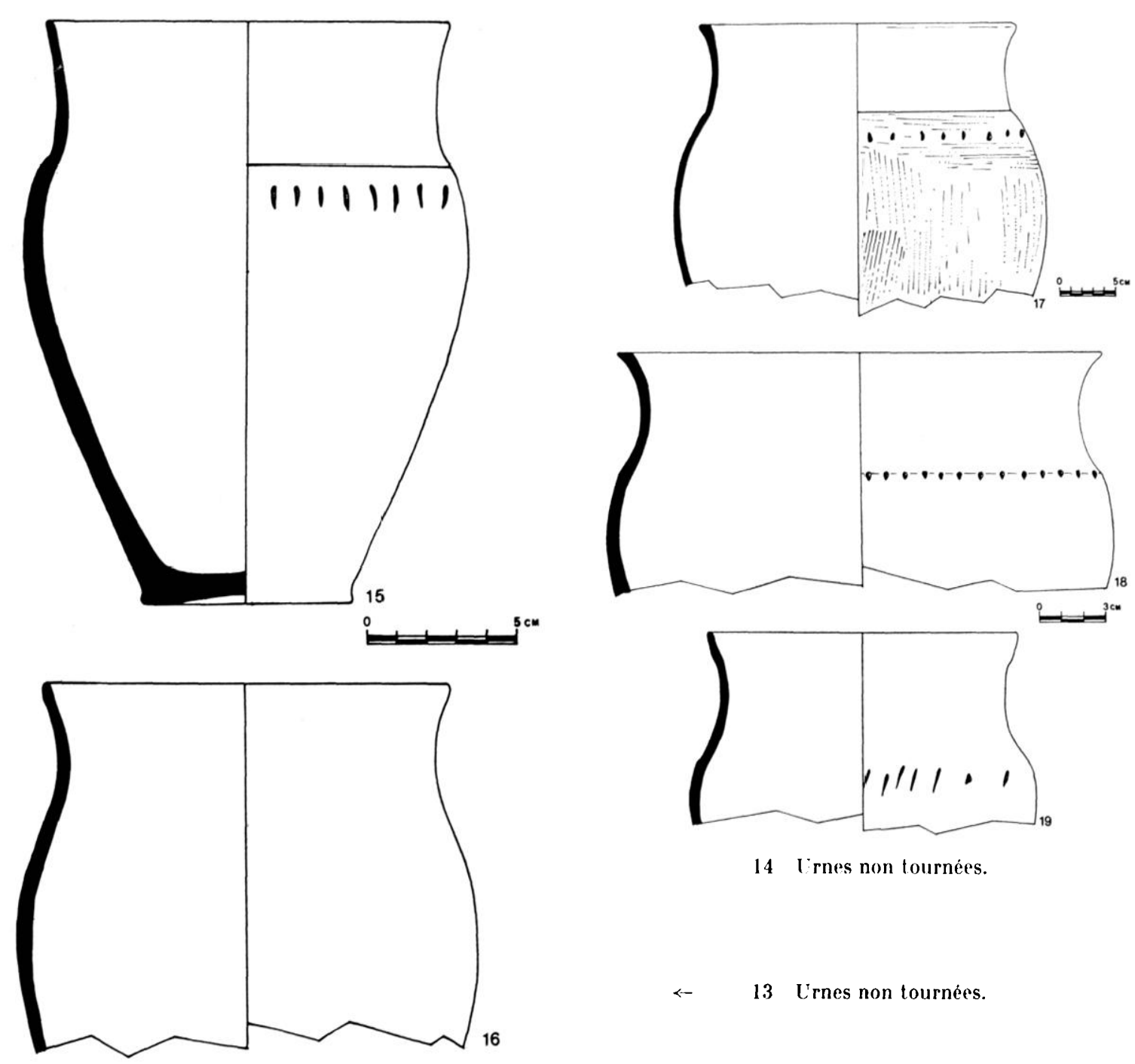

14 Irnes non tournées.

«- $\quad 13$ Urnes non tournées.

extérieure des vases présente toujours le même aménagement pour le col et pour la panse : polissage (état $n^{0} 1$ ) : 12 cas ; lissage fini (état $n^{0} 2$ ) : 21 cas.

\section{DeuxiÈme SÉrie D'URnes.}

Dans ce groupe, nous rangeons des urnes à panse surhaussée et peu galbée. Elles ont un col haut à profil arrondi plus ou moins concave, mais nettement moins important que la panse. Le contact col-panse peut être anguleux ou adouci. Les trois types de col (divergents, parallèles et convergents) sont attestés. Le seul fond connu est creux. On compte dans cette série 61 vases, soit $23,4 \%$ du total de la céramique non tournée et $52,4 \%$ des urnes. Nous décrivons un exemplaire complet et 7 exemplaires en partie conservés.

Fig. 13, $\mathrm{n}^{0} 15$ : urne complète (inv. GS 125) de forme $222 \mathrm{~A}$; bord CO 1; fond $22 \mathrm{~B}$; rapport 120. Le décor est situé sur l'épaule et composé d'une rangée horizontale de coups incisés verticalement. 

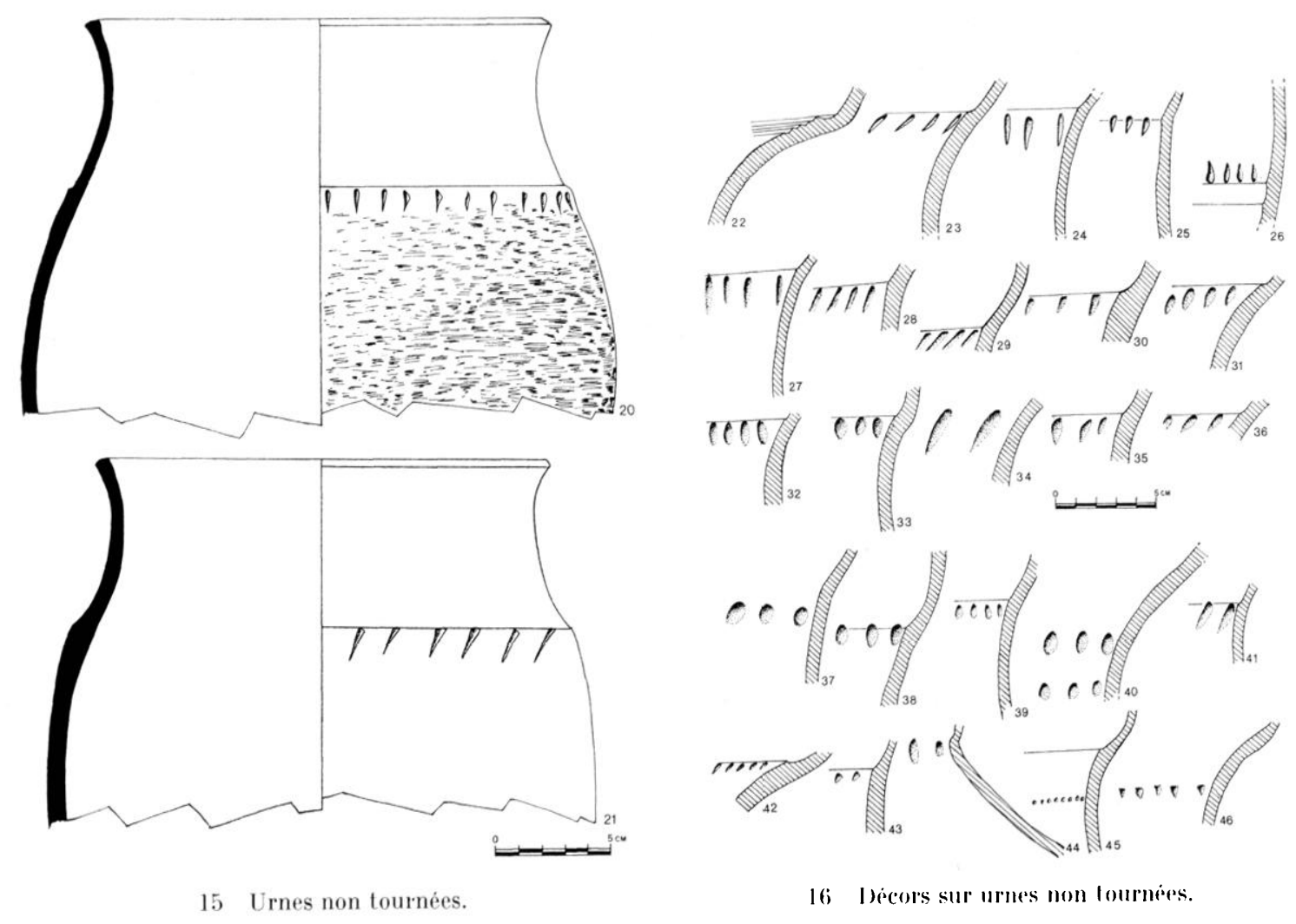

16 Jecors sur urmes non tournees.

Dégraissant mal calibré de calcaire et calcite broyés et de mica. Aménagement des surfaces : extérieur $n^{0} 2$ pour le col et le haut de la panse, $n^{0} 3$ pour le bas de la panse; intérieur $n^{0} 2$.

Figr. 13, $\mathrm{n}^{0} 16$ : partie supérieure d'urne (inv. 136); bord I)() 1; col divergent à contact col-panse adouci. Dégraissant bien calibré de calcaire et de mica. Aménagement des surfaces no 2 partout. extérieur comme intérieur.

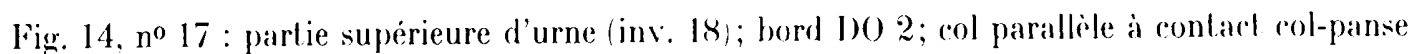
anguleux. Décor sur l'épaule : rangée horizontale d'impressions. Iégraissant mal calibré de calcaire et de mica. Aménagement des surfaces : extérieur $n^{0} 2$ pour le col, $n^{0} 4$ (raclage) pour la panse; intérieur : $\mathrm{n}^{0} 2 / 3$.

Fig. 14, no 18 : partie supérieure d'urne (inv. 8:31); bord Co 4; col parallile à profil tries incurvé. Le contact col-panse est anguleux el décoré d'une rangée horizontale de petites impressions. Dégraissant mal calibré de calcaire broyé el de mica. Les surfaces présentent l'aménagement suivant: à l'extérieur $n^{0} 2$ partoul. à l'intérieur $n^{0} 2$.

Fig. 14, no 19 : partie supérieure d'urne (inv. 100); bord J)() 1; col parallite à contact rolpanse adouci. Décor sur l'épaule d'une rangée horizontale de coups incisés obliques. Dégraissant bien calibré de calcaire broyé et de mica. Aménagement des surfaces : extérieur et intérieur $n^{0} 2$ sur le col et la panse.

Fig. 15, $\mathbf{n}^{0} 20$ : partie supéricure d'urne (inv. 120); hord C() 4 ; col convergent à contact colpanse anguleux. Le décor est situé sous le conlact du col et de la panse et constitué par une rangée horizontale de coups incisés profondément el verticalement. Dégraissant mal calibré de calcaire broyé et de mica. Aménagement des surfaces : à l'extérieur et à l'intérieur. $n^{0} 2$ pour le col et no 3 pour la panse. 
Fïg. 15. no 21 : partie supérieure d'urne (inv. 2); bord $\mathrm{Co}$ 4, col convergent à contact col-panse anguleux. sous lequel se trouve une rangée de coups incisés obliquement. Dégraissant mal calibré de calcaire broyé et de mica. Aménagement des surfaces : $n^{0} 2$ pour le col et $n^{0}: 3$ pour la panse.

L'étule conjointe des frazments et des formes plus completes nous conduit à définir ainsi les caracteres grenéraux de la série : la seule forme globale attestee est 222 $\mathrm{B}$; les bords sont dans l'ordere diecroissant de fréquenere: bords (0) 1 (26 ex.), bords 1001 (15 ex.),

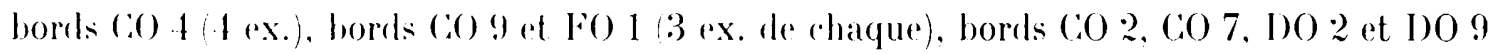

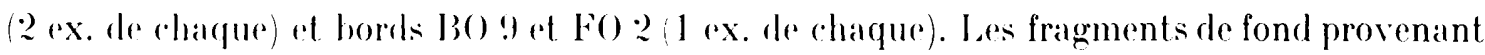
de la fouille ef dont on trouvera ci-apres lanalyse. ne pouvant être à coup sùr rapportés à une serie particulière de formes, seul le fond de l'urne complete (fig. 13, no 15) est à considerer ici : c'est un fond 2.2 B. La majorité des urnes de la deuxième série est ornée sur l'épaule. plus ou moins prese du contact du col et de la panse. Dans tous les cas il s'agit l'une rangée horizontale d'impressions ou de coups incisés. Nous figurons (fig. 16, nos $23-43$ at fo-46) les divers motifs décoratifs attestes sur les fragments d'urne de la série 2 .

Les mèmes catégories de dégraissant que précédemment se rencontrent : aalcaire ot mica : 18 ex. $(76,8 \%)$; calcaire, calcite et mica : 11 ex. $(17,6 \%)$; -- calcaire, quartz al mica : 3 ex. $(4.8 \%$ \%

Dans 2) (as, ces inclusions sont bien calibrées, et dans 37 cas elles sont mal calibrées. L'observation de l'amenagement des surfaces a pu porter sur le col et la panse de 8 vases : $1 \mathrm{ont}$ un aménagement identique (lissage fini) et 4 ont un rol plus soigné que la panse (rans 3 (als, lissage fini of lissage bbauché et dans un cas lissage fini et raclage). Ailleurs, l'analyser n'a porté que sur les rols dont 39) exemplaires ont un lissage fini, 12 un lissage ébauché et un seul n'est pas aménagé.

\section{3. 'Tromsìme série d'URNes.}

Cette troisième série concerne des urnes à lécor excisé : six exemplaires, soit $2,2 \%$ du total des vases non tournés et $5,1 \%$ des urnes.

Fï. 2:3, no 81 : rol et panse d'urne (inv. (is 1:3). Bord $\mathrm{CO}$ ) 1 ; col bas divergent a contact colpanse adouci; panse à profil arrondi peu galbé. Le décor est situé de part el d'autre du diamètre maximum de la panse sur une bande horizontale de $3.4 \mathrm{~cm}$ de large. Il se compose de bas en haut de :2 larges traits profondément incisés, horizonlaux et paralléles; 1 bande qui comprend deux motifs alternés. séparés par des carrés réservés : damiers excisés et triangles excisés dégageant une ligne brisée champlevée, elle-mème décorée par deux lignes brisées incisées au brunissoir; à nouveau, deux larges traits incisés, horizontaux et paralleiles. Dégraissant mal calibré de calcaire broyé et de quart\%. Aménagement des surfaces : extérieur el intéricur no 1 . col et panse.

Fï. 24. $\mathrm{n}^{\circ} 8: 3$ : (col et épaule d'urne (ins. Gis 15); bord 30 9; col haut divergent a contact col-panse anguleux. Le décor excisé intéresse deux parties du vase. Tout d'abord, à l'intérieur sous le bord, se trouve une double série de triangles excisés, superposés et de mème sens, dégageant des triangles champlevés. Ilu décor de la partie supérieure de la panse ne subsiste qu'une double ligne brisée champlevée. Le dégraissant est bien calibré el se compose de calraire broyé et de mica. Aménagrement des surfaces : extérieur el intérieur $n^{0} 1$.

Fig. 21. no 8.1 : fragment de panse d'urne (inv. (is 21); arène adoucie; le décor conservé se compose de haut en bas d'une double série de triangles exrisés superposés et de mème sens, base 


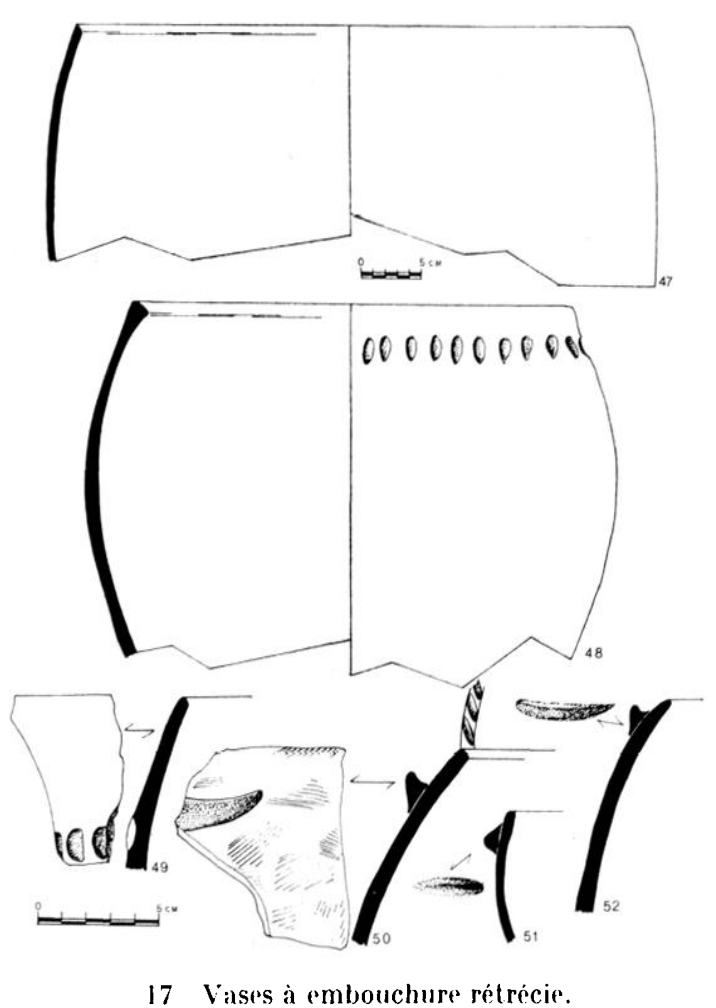

17 Vases à embouchure rétrécie.

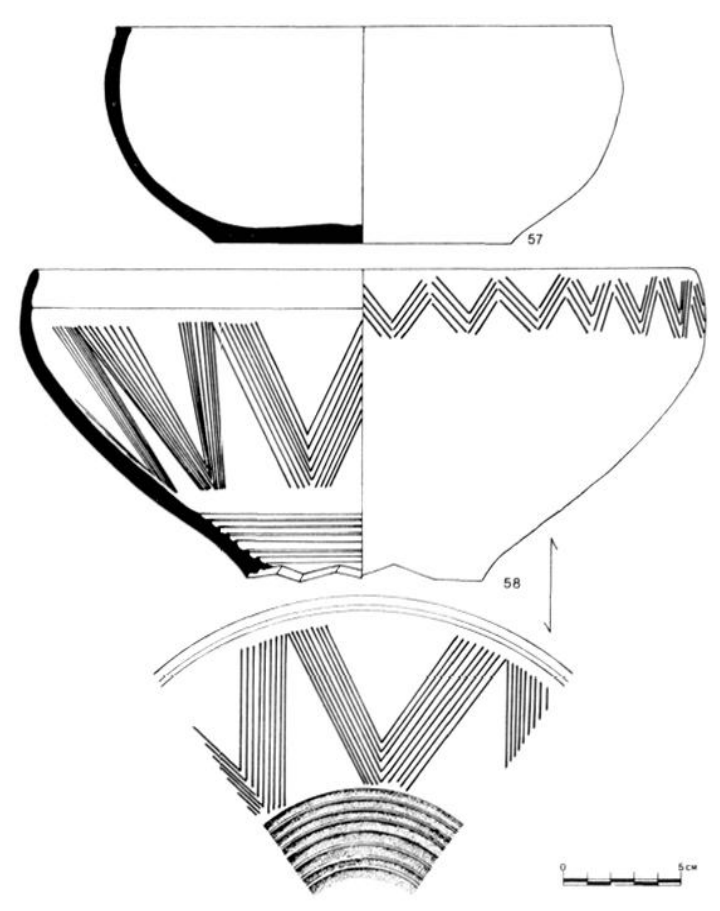

19 Coupes à bord convergent en céramique non tournée.

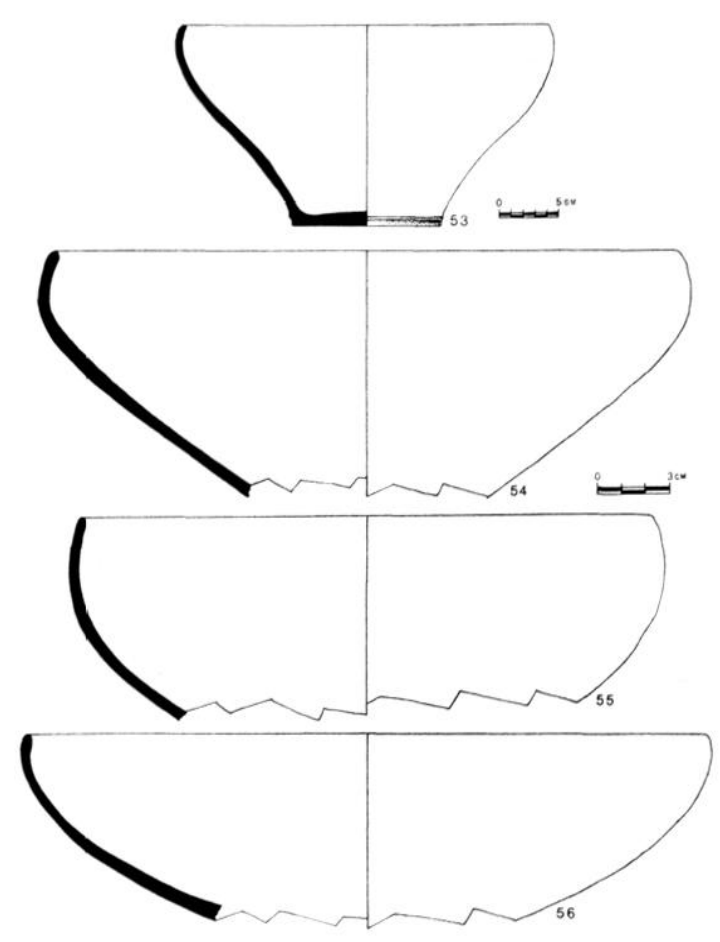

In coupes a bord convergent en céramique non tournere.

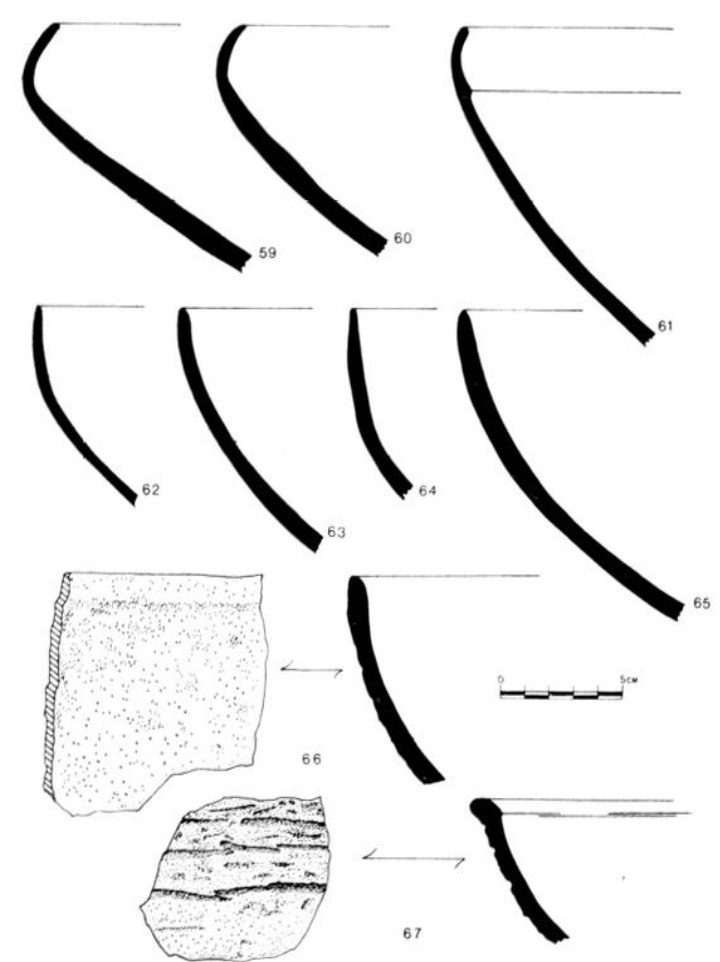

20) Coupes non tournées : 59-61 : coupes à bord convergent ; 62-66 : coupes à bord parallèle; 67 : coupe à bord divergent. 
vers le haut, dégageant des triangles champlevés; d'une série de motifs emboités; enfin, d'une double série de triangles excisés et emboîtés délimitant une liơne brisée champlevée. Dégraissant bien calibré de calcaire broyé et de mica. Aménagement des surfaces : extérieur et intérieur $\mathrm{n}^{0} 2$.

Fig. 24, no 85) : partie supérieure d'urne (inv. GS 24); bord C 21; col haut et diveronent à contact col-panse anguleux. Panse carénée probablement haute. Le décor excisé prend place à l'intérieur sous le bord (double série emboitée de triangles excisés délimitant une ligne brisée champlevée) et sur la partie supérieure de la panse (de haut en bas : le mème motif qu'à l'intérieur du col surmontant un motif complexe de lignnes courbes et droites). Dégraissant bien calibré de calcaire et de calcite broyés; aménagement des surfaces $\mathrm{n}^{0} 1$ partout, col et panse.

Fig. 24, no 86 : col divergent d'urne (inv. GS 14); bord C 11. Le décor excisé, à l'intérieur sous le bord, est composé d'une double série de triangles excisés, superposés et de même sens, dégageant des triangles champlevés. Dégraissant bien calibré de calcaire et de calcite broyés et de mica. Aménagement des surfaces : extérieur et intérieur $n^{0} 1$.

Col divergent d'urne (inv. J 2 3 B); bord C 19; le décor excisé se trouve à l'intérieur sous le bord. Il est formé d'une rangée simple de triangles excisés. Dégraissant bien calibré de calcaire broyé et de mica; aménagement des surfaces : intérieur et extérieur $\mathrm{n}^{0} 2$.

\section{Quatrik̀me série d'unNes.}

La quatrième série d'urnes comprend des vases sans col à embouchure rétrécie et à panse à profil arrondi. Elle compte 17 exemplaires, ce qui représente $6,5 \%$ du total des vases non tournés et $14,5 \%$ des urnes (fig. 17, nos 47 à 52). Les caractères des vases de cette série sont les suivants : les bords ont pour forme, dans l'ordre décroissant de fréquence, bord HO 1, $6 \mathrm{ex}$; hord IO 5, $3 \mathrm{ex}$; bord IO 1, 2 ex. ; bords GO 1, HO 2, HO 4, HO5, IO 2 et $109: 1 \mathrm{ex}$. de chaque. Un même type de décoration (rangée horizontale d'impressions ovalaires) se rencontre sur quatre vases, soit sur la lèvre (fig. 17, no 50), soit sous le bord (fig. 17, no 48), soit à la partie supérieure de la panse (fig. 17, no 49). Trois de ces vases (fig. 17, nos 50,51 et 52 ) possèdent des oreilles de préhension.

Ici encore se rencontrent les trois catégories habituelles de dégraissant : calcaire et mica : 11 ex. $(64,9 \%)$; - calcaire, calcite et mica : 4 ex. $(23,6 \%)$; - calcaire, quartz et mica : 2 ex. $(11,8 \%)$.

Ces inclusions sont mal calibrées dans 15 ) cas, et bien calibrées dans 2 cas. Enfin, huit vases présentent à l'extérieur un lissage fini, six un lissage ébauché, deux un raclage et un seul un peignage.

\section{Coupes i profil arrondi-convexe.}

Les coupes à profil arrondi-convexe sont au nombre de 121 , soit $46,5 \%$ du total des vases et $83,4 \%$ des coupes. On distingue parmi elles les coupes à bords convergents les coupes à bords parallèles et les coupes à bords divergents.

1. Coupes à bords convergents (fig. 18 à 20 , nos 53 à 61 ).

81 coupes ont ce type de bord, soit $31.1 \%$ du total des vases non tournés, $55,9 \%$ du total des coupes ou encore $67,2 \%$ des coupes à profil arrondi-convexe. Voici la description de quatre exemplaires complets ou particuliers. 
Fig. 18. no 5:3 : coupe de forme 421 (inv. (is 1); bord IO 1; fond 1:3 B; rapport 47. Le fond présente à l'extérieur un listel horizontal. Dégraissant mal calibré de calcaire broyé el de micia. Iménaquement des surfaces identique à l'inlérieur el à l'extérieur: $n^{\circ} 1$.

Fig. 19, no 57 : coupe de forme 421 (inv. (sis 99); bord I0 2; fond 11.1 ; rapport is. Le fond présente des traces d'usure. Jénraissant mal calibré de calcaire el de calcite broyés, de mica et de quart\%. Aménagement des surfaces, à l'extérieur comme à l'intérieur. $\mathrm{n}^{0} 2$.

Fig. 19. $\mathrm{n}^{\mathrm{0}}$ is : coupe presque complite (inv. (is 2:3); bord I() 1. présentant un ressatut a l'intérieur sous la lève. Ce vase est décoré a l'inlérieur sous le bord el à l'intérieur sur toute la surface de la panse. I l'extérieur. le motif se compose de quatre lignes brisées superposćes tracées au brunissoir; a l'intérieur, il s'agit de sept à neuf chevrons emboillés el rayonnants. tracés au brunissoir, complétés vers le fond par sept cannelures étroites et horizontales. I.e dégraissant se compose de calcaire broyé et de mica mal répartis; les surfaces sont aménagées de façon identique à l'extérieur et à l'intérieur, $n^{0} 1$.

Fïg. 20. no 61 : panse el bord de coupe (inv. (is 22); bord I0 1. présentant un ressaut a l'intérieur sous la livre. Dégraissant très mal calibré de calcaire et de calcite broyés et de mica; la surface intérieure est plus soignée $\left(\mathrm{n}^{\circ} 1\right)$ que la surface extérieure $\left(\mathrm{n}^{\circ} 2\right)$.

si l'on joint à ces vases l'étude des fragments de vases de mème forme, on constate que la série présente les caracteres suivants : deux vases sont complets et ont une forme 421 ;

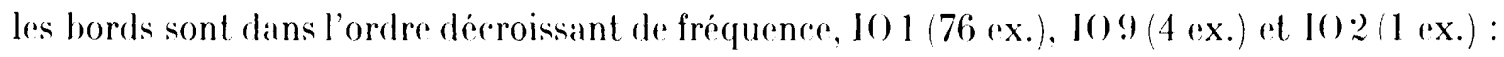
les lèvres arrondies sont donc très largement majoritaires. Les fonds connus sont de

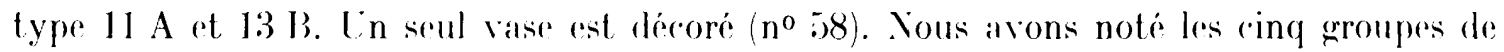
degraissant suivants : (alleaire ot mica : 65) (ass $(78 \%)$; - ralcaire, calcite et mica : 10 (ass $(12,3 \%)$; - calcaire, calcite, mira et quartz : 3 cas $(3,6 \%)$; ralcaire cet calcite : :2 cas $(2,4 \%) ; \cdots$ - calcaire, calcite, mica et schiste : 1 (as $1,2 \%)$.

Cés inclusions sont bien callibrées dans 40 cas, mal calibrées dans 41 cas. L'aménagement des surfaces est irlentique à l'intérieur et à l'extérieur pour 46 de ces coupes (polissage : 11 , lissage : 35)). La surface est mieux aménagée à l'extérieur qu'à l'intérieur sur 26 coupes (polissage et lissage fini : 2.3 ; polissage el lissage ébauché : 1 ; lissage fini et lissage ébauche : 2). Elle est moins bien aménagée à l'extérieur qu'à l'intérieur dans is cas (lissage fini al polissage : 1 ; lissage ebauche et lissage fini : 3 ; lissige ebauthé aver raclage vers le bas de la panse et lissage fini/ébauché : 1) (fig. $\left.20, n^{0} 665\right)^{9}$.

\section{Coupes à bords parallèles (fig. 20, nos $62-66$ ).}

Au nombre de 30 exemplaires, tous fragmentaires, ces coupes representent 11,5\% du total des vases. $20.7 \%$ des coupes et $24,9 \%$ des coupes à profil arrondi convexe. Les caracteres généraux en sont les suivants : les bords ont pour forme, dans l'ordre décroissant de fréquence, FO 1 (26 ex.), FO 9 (3 (ex.) et FO 5 (1 ex.). Nous avons déterminé quatre catégories de dégraissant : calcaire el mica : 19 cas $(62,7 \%)$; - alcaire, calcite et mica : 8 exemplaires $(26,4 \%)$; - calcaire, calcite quartz et mica : 2 as $(6,6 \%)$; - calcaire, calcite, mica et matière organique : 1 cas $(3,3 \%)$.

Ces inclusions sont mal calibrées dans 14 cas et bien calibrées dans 16 . Pour 26 de 
ces coupes, la surface extérieure et la surface intérieure ont un aménagement identique (polissage : 6 ; lissage fini : 19 ; lissage ébauché : 1 ). La surface extéricure est mieux aménagée que la surface intérieure dans 3 cas (polissage et lissage fini). Enfin, la surface extérieure est moins bien aménagée que la surface intérieure dans 1 cas (lissage ébauché et lissage fini).

3. Coupes à bords divergenls (fig. :20, $\mathrm{n}^{0} 67$ ).

Il y a 10 vases de ce type. Lous fragmentaires, soit $3.8 \%$ du total de la céramique non tournée. $6.9 \%$ des coupes et $8.3 \%$ des coupes à profil arrondi convexe. Les bords présentent trois formes : bord $\mathrm{EO} 1(8 \mathrm{ex}$.) ; hords $\mathrm{EO} 2$ et $\mathrm{EO} 4(1$ ex. de chaque). Les dégraissants sont de trois types : calcaire et mica : 7 cas ; - calcaire, calcite et mica : 2 cas ; - calcaire, calcite, mica et quartz : 1 cas.

Les inclusions sont mal calibrées pour 6 vases et plutòt mal pour 4. L'aménagement des surfaces est identique à l'extérieur et à l'intérieur pour 8 de ces coupes (polissage : 1 ; lissage fini : 7). La surface extérieure est moins bien aménagée que la surface intérieure dans un cas (surface non aménagée avec enfoncements linéaires à l'extérieur ${ }^{10}$ et lissage fini à l'intérieur).

\section{Les COUPELLES.}

La catégorie des coupelles est forte de 16 unités, r'est-à-dire qu'rlle représente $6,1 \%$ du total des vases et $11 \%$ des coupes.

1. Coupelles à bords convergents (fig. 21, no 69).

Elles sont au nombre de sept, soit 2,6\% du total des vases non tournés ou 4,8\% des coupes. Ieurs bords ont deux formes 109 (4 ex.) et IO 1 (3 ex.). Le dégraissant de ces vases est soit du calcaire broyé et du mica (6 ex.), soit du calcaire broyé, du mica et du quartz (1 ex.). Cés inclusions sont mal calibrées dans 4 cas, bien calibrées dans 3. Less surfaces sont identiques à l'extérieur et à l'intérieur, lorsque l'examen est faisable (polissagre 1 fois ; lissage fini, j) fois).

2. Coupelles à bords parallèles (fig. $21, \mathrm{n}^{08} 68,70$ et 71 ).

Il y a huit coupelles de ce type, soit $3,1 \%$ du total des vases et $5,5 \%$ des coupes. Une de ces coupelles est complète :

Fig. 21, no 68 : coupelle de forme 442 (inv. (Gs 10); bord FO 1 ; fond $21 \mathrm{~A}$; rapport 39. Dégraissant mal calibré de calcaire broyé et de mica; aménagement des surfaces identique à l'extérieur et à l'intérieur : $\mathrm{n}^{0} 2$.

Cette série a pour caractères des bords FO 9 (4 ex.). FO 1 (3 ex.) et FO 5) (1 ex.). Les dégraissants rencontrés sont de trois types : calcaire et mica : j exemplaires ; -... calcaire, mica et calcite : 2 exemplaires ; - calcaire, mica et quartz : 1 exemplaire. 


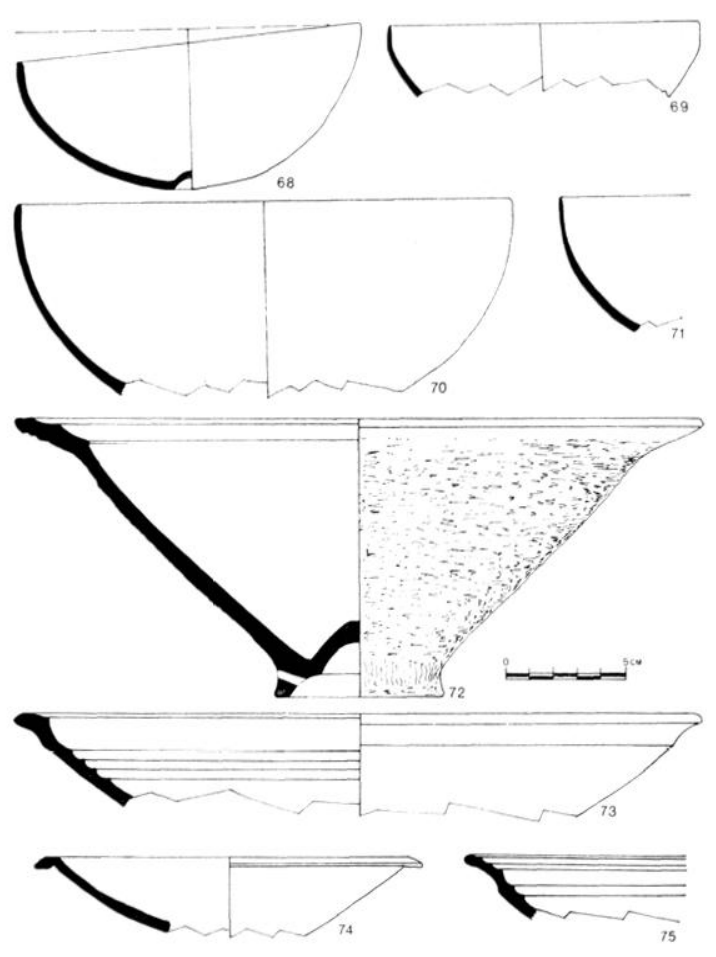

21 Coupetes el coupes à bord facelí en céramique non tournere.

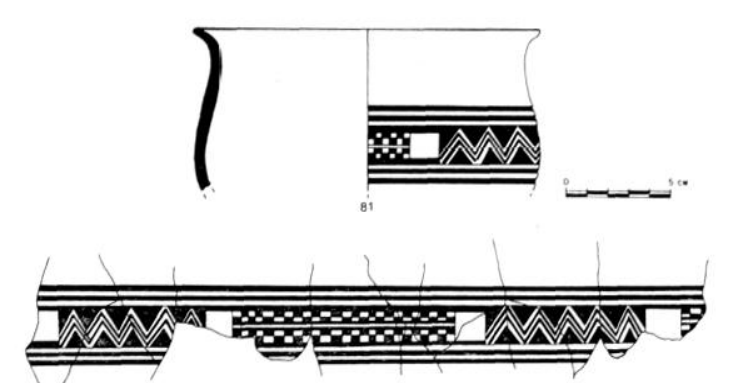

23 Vase non fourné à décor excisé.

24 Vases non lournes à décor excise.
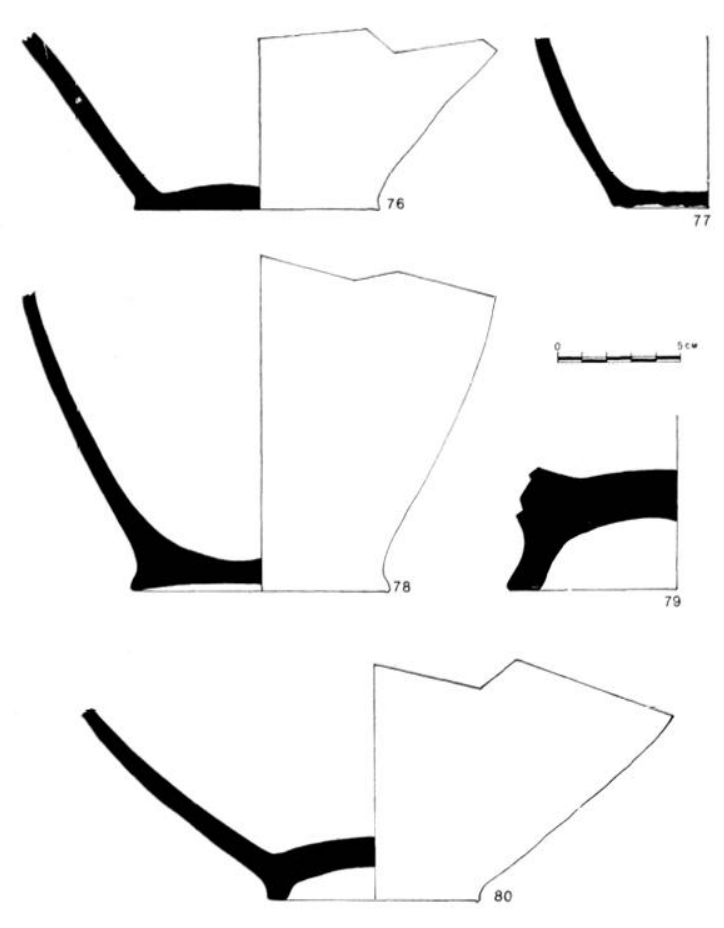

22 Fonds de vases non tournés.

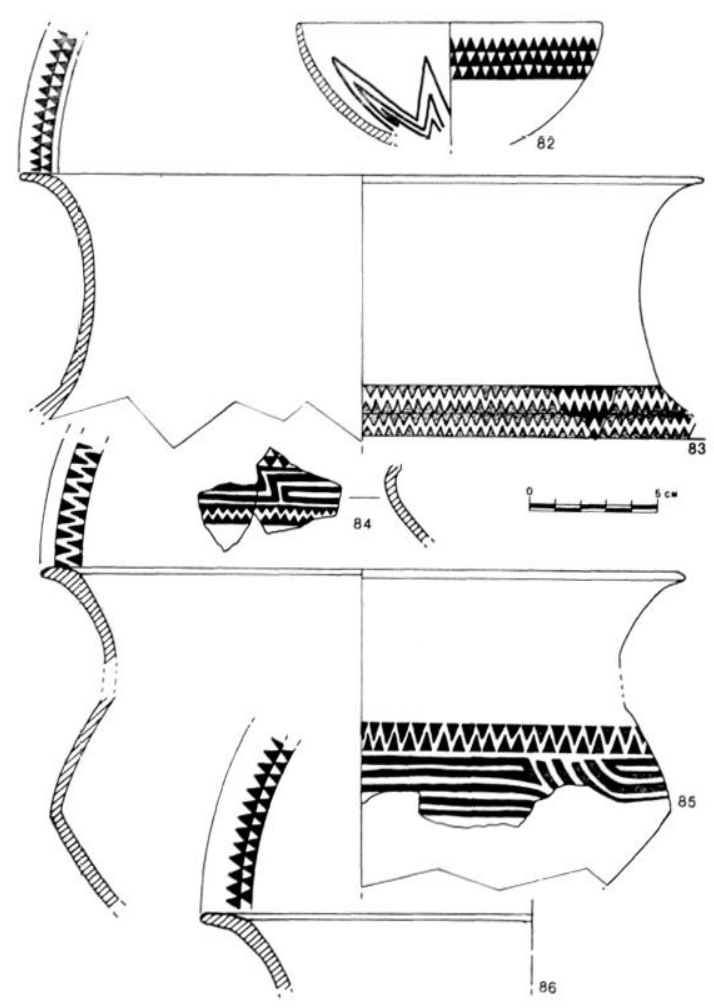


Dans six cas, ces inclusions sont mal calibrées, dans deux cas elles le sont bien. Les surfaces sont toujours aménagées de façon identique à l'extérieur et à l'intérieur (lissage fini : 7 cas ; lissage ébauché : 1 cas).

\section{Coupelle à décor excisé.}

Une coupelle (fig. 24, no 82) porte un décor excisé (inv. (is 16). La forme est 441 ou 442, le bord FO 1, le fond manque. Le vase est décoré à l'extérieur et à l'intérieur. İ l'intérieur, il s'agit d'une triple ligne brisée formant un décor rayonnant; à l'extérieur, c'est une triple série de triangles excisés, pointe en haut, dégageant des triangles champlevés. Le dégraissant, bien calibré, est composé de calcaire et de mica. La surface intérieure (polie) est mieux aménagée que la surface extérieure (polie et lisséc).

\section{LEs coupes tronconiques.}

C'est unc classe de coupes particulières et peu représentée 7 ex. formant $2,6 \%$ du total des vases et $4,8 \%$ des coupes). Ln exemplaire est complet :

Fig. 21, $\mathrm{n}^{0} 72$ : coupe tronconique (inv. 135) de forme 326 ; bord B 21 ; fond $62 \mathrm{~A}$; rapport 37. Le fond présente à l'intérieur du vase un ombilic aplati et sous le fond un coup de raclette avant cuisson. Deux trous de suspension diamétralement opposés se trouvent sur la paroi du fond. Dégraissant mal calibré de calcaire broyé, de mica et de quarl\% roulé. Aménagement des surfaces: $n^{0} 1$ à l'intérieur, no 4 (raclage) à l'extérieur.

Les bords de la série des coupes tronconiques permettent de distinguer deux types : les coupes à lèvre épaissie présentant un aplatissement horizontal : bord FO 7 ( 2 ex.) (fig. $21, \mathrm{n}^{\circ} 73$ ) et bord BO 7 (1 ex.). Un autre type est constitué par les bords à méplats, de forme A 11 ( 1 ex.) (fig. 21, no 74), BO 1 (1 ex.) et B 21 (2 ex.) (fig. 21 , nos 72 et 75). Quclques-unes de ces coupes sont décorées intérieurement de cannelures horizontales (fig. 21, nos 73 et 75 ).

On retrouve pour les coupes tronconiques les trois dégraissants les plus courants : calcaire, calcite et mica : 3 cas ; - calcaire et mica : 3 cas ; calcaire, mica et quartz: 1 cas.

Quant aux surfaces, elles sont aménagées de trois façons : un aménagement égal pour l'intérieur et l'extérieu:, soit polissage (1 cas), soit lissage fini ( 2 cas) ; une surface intérieure mieux aménagée que la surface extérieure (polissage et raclage : 1 cas ; polissage et lissage ébauché : 1 cas; lissage ébauché et surface non aménagée : 1 cas); enfin, une surface intérieure moins soignée que l'extérieur (lissage fini et polissage). I noter que les coupes à bord faceté du type $B 21$ ont toutes une surface intérieure nettement plus soignée que la surface extérieure ( 1 et 3 ou 5 ).

\section{LES FONDS DE VASE (fig. 22).}

Pour finir, signalons une abondante série de fonds $(22$ ex.) qui ne sauraient être rapportés à une forme précise de vase. Les types représentés sont les suivants : 1 fond $11 \mathrm{~A}$; 4 fonds $11 \mathrm{~B}$ (fig. $22, \mathrm{n}^{0} 77$ ) ; 3 fonds $12 \mathrm{~A} ; 6$ fonds $12 \mathrm{~B}$ (fig. $22, \mathrm{n}^{\circ} 76$ ) ; 1 fond $13 \mathrm{~A}$; 


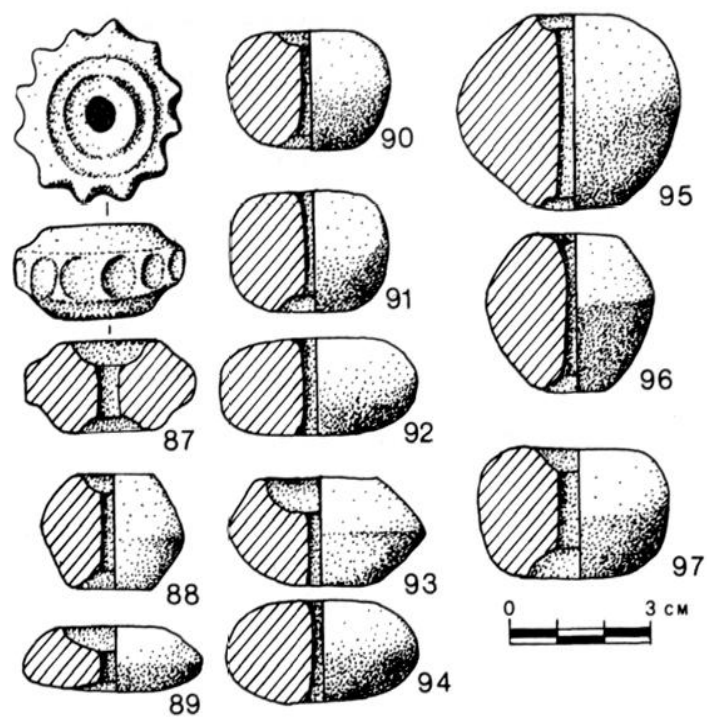

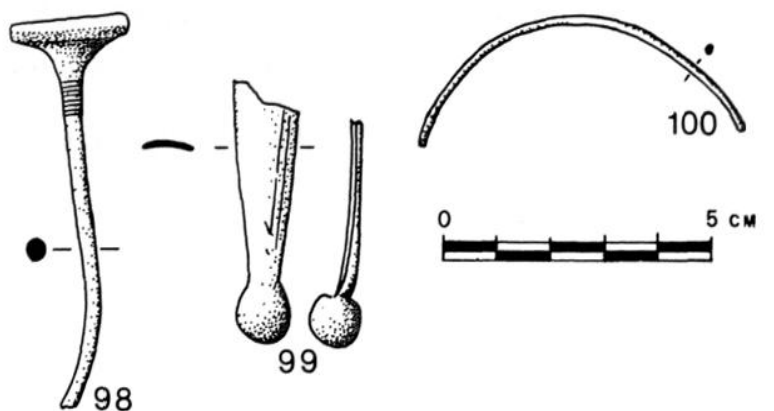

26 Objets in bronze.

25) Fusaïoles en torre cuite.

1 fond $21 \mathrm{~B} ; 1$ fond $22 \mathrm{~A} ; 2$ fonds 41 A (fig. $22, \mathrm{n}^{0} 80$ ) $; 1$ fond $61 \mathrm{~A} ; 1$ fond $62 \mathrm{C}$; 1 fond $6.3 \mathrm{IB}$ (fig. $2.2, \mathrm{n}^{0} 79$ ).

\section{Fusaïloles}

Les niveaux protohistoriques de la Grotte Suspendue ont livré 11 fusaïoles en terre cuite de formes et de tailles diverses (fig. $25, n^{0 s} 87$ à 97). Quatre d'entre elles sont aplaties ( $\mathrm{n}^{0 \mathrm{~s}} 87,89,92$ et 94$)$, trois sont carénées ( $\mathrm{n}^{\text {os }} 88,93$ et 96 ) et quatre autres sont arrondies ( ${ }^{08} 90,91,95$ et 97). Lne scule est ornée d'une rangée d'impressions ovalaires, disposée sur le plus grand diamètre de l'objet, de telle sorte que vu de dessus, il forme un cercle crénelé. La matière employée pour toutes ces fusaïoles est identique à celle qui a servi à monter les vases non tournés.

\section{Mobilier métalligue}

Il s'agit de trois objets en bronze :

Fìn. 26, no $^{\circ} 98$ : épingle à tête large et discoüdale en forme de tête de clou, du groupe L de F. Audouze et J.-C. Courtois ${ }^{11}$. La tige a une section ronde et présente vers la tête huit incisions fines et paralleles.

Fig. 26, no 99 : fragment de bracelet ouvert à section plate et extrémité bouletée. Le jonc est orné, sur la partie extérieure. de deux incisions fines et parallèles au bord.

Fig. 26, no 100 : fragment de bracelet-armille en bronze, a section ronde.

\section{Мobilier lithigue}

Il faut signaler pour finir plusieurs objets en pierre: il s'agit de fragments de meules plates et de broyeurs, de quelques lissoirs en pierre dure et d'une série de disques taillés

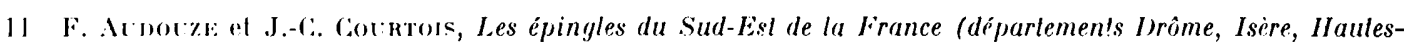
Alpes, Savoie el IIaule-Saroie), dans Prähistorische Bronzefunde, XIII, 1, München, 1970, p. 30-32 et pl. 8, no 218. 
dans des lauses calcaires, souvent échancrés. dont on perut penser qu'ils servirent de couverele de vase. Ce mobilier lithique provient en majeure partie de la zone du fond de la grotte (fig. 7).

\section{DATATION HT INTERPRETATION}

L'étude typologique ot comparative du mobilier dont nous venons de donner un inventaire descriptif fait apparaite trois ansembles chronologique: : le premier est de la fin du vire s. el des alentours de 600; le second de la deuxiem: moitié du vie s. al. J.-li. Cous rangeons dans un troisieme groupe les pièees dont la date ne peut ètre précisée à lintérieur lu vies.

\section{Groupe ancien.}

Dans le groupe ancien, on placera tout d'abord le skyphos de type rhorlien no 1 . Ca type de coupe engobee est très courant en Girece d'Orient ainsi que dans les colonies ioniennes et leurs alentours. Il appartient à une série qui comprend trois variantes : le skyphos à l'oiseau, le skyphos à roselles poinlées et. comme ici, le skyphos à bandes ${ }^{12}$. Le skyphos à bandes est notamment attesté à llistrial ${ }^{13}$ at à syphnos ${ }^{14}$. En Occident, on le trouve dans un tumulus de Claps, pres d'Aix-en-Provence ${ }^{15}$. Les deux autres variantes à l'oiseau et à rosettes sont aussi présentes à la Couronne ${ }^{16}$. à Saint-Blaise ${ }^{17}$ et à Varseille ${ }^{18}$. la datation des trois variétés est identique et repose en partie sur la stratigraphie d'histria où l'on trouve en particulier le skyphos à bandes dans la strate archaïque I datée du dernier quart du vire s. et des premières années du $v^{2}{ }^{e}$ s. av. J.- $\left({ }^{19}{ }^{19}\right.$. Des datations semblables ont été obtenues en Sicile à Megara Hyblaea et à Syracuse ${ }^{21}$, et en Gaule du sud à La Couronne ${ }^{22}$.

Les comparaisons que suggèrent les urnes en céramique non tournée de la première série, à grandl col divergent et panse galbée, nous portent vers la même période. Lin effet, cette forme se renconte dans une strate ancienne de La Liquière de Calvisson (Gard)

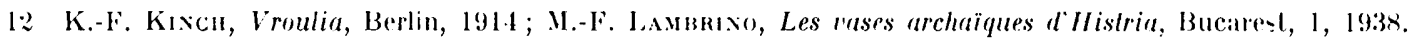

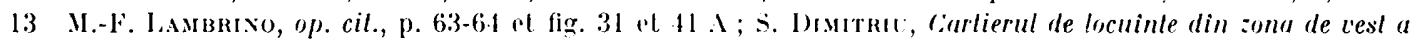

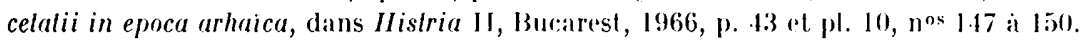

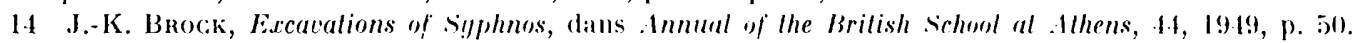

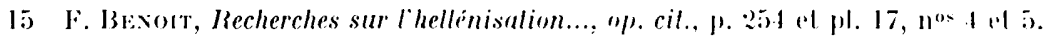

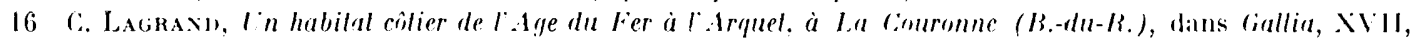

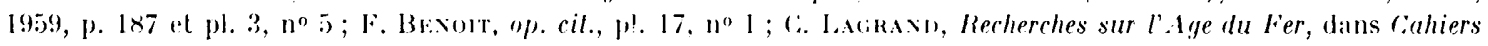

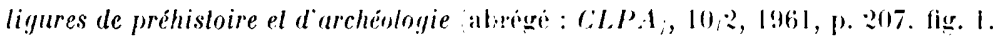

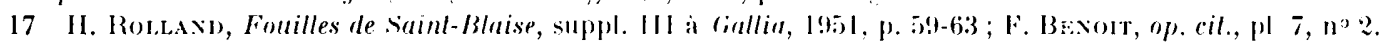

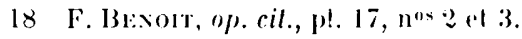

19 S. 1)motrit, Carlierul..., op. cil., p. 13.

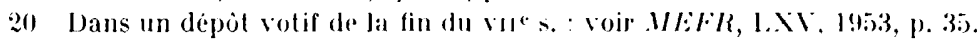

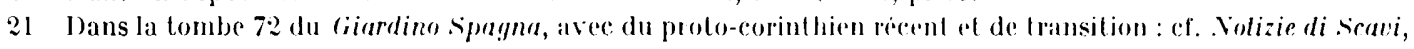
1925, p. $20 \%$, fig. 37 .

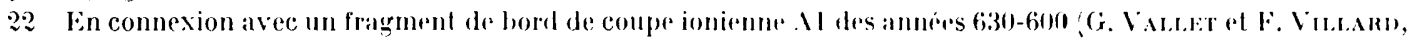
Megara Iybb!aea, op. cil., p. 15-16. 
(fig. 35, $\left.n^{0} 160\right)^{23}$ et dans l'habitat de Port-Vielh à Aigues--Mortes (Gard) (fig. 35, no 159)24. Par ailleurs, les urnes à grand col divergent, panse galbée et pied haut ou bas sont fréquentes en Languedoc occidental à la fin du vir ${ }^{\mathrm{e}}$ s. au Grand Bassin I (Mailhac, Aude) ${ }^{25}$ et à Recobre (Quarante, Hérault) ${ }^{26}$; et dans la première moitié du vi ${ }^{e}$ s. à Saint-Julien (Pézenas, Hérault $)^{27}$. De plus, les vases $n^{\text {os }} 3$ et 4 sont très comparables tant pour la forme que pour le décor, à un vase de la tombe 46 de la nécropole d'Agullana (Gerona) ${ }^{28}$. On remarquera d'ailleurs que les décors de vases apportent des arguments dans le même sens ${ }^{29}$.

En autre type de vase non tourné est incontestablement ancien : il s'agit des coupes à bord à méplats, qui sont très fréquentes dès le Bronze final III b et notamment dans le faciès Mailhacien $\mathrm{I}^{30}$, avec par ailleurs un aménagement des surfaces semblables. Ces coupes existent encore, mais plus rarement, à La Liquière I et à Port-Vielh.

Les deux exemplaires de coupes arrondies-convexes à bord convergent et à ressaut interne ( ${ }^{05} 58$ et 61) trouvent à La Liquière I a (fig. 35, no 161$)^{31}$ et à Port-Vielh quelques correspondants.

Le type de l'épingle à tête discoüdale nº 98 apparaît aussi en Languedoc dès le Mailhacien $\mathrm{I}^{32}$.

Il semble donc que nous ayons là un ensemble homogène qui peut être daté des alentours de 600 av. J.-C..

Groupe récent.

Les documents suivants appartiennent à un groupe plus récenl : le pied de coupe pseudo-ionienne $\left(\mathrm{n}^{0} \stackrel{2}{2}\right)$ présente les caractères les plus tardifs de la série des imitations

23 Cabane 1.10/1971, decapages 4 et j. Ces deux decapages font parlie de lhorizon la de I.a Liquiere ou les seules importations sont d'origrine etrusque amphores et canthare de Bucchero Nero, scellé par des couches datés des alentours de 600 La liquiere Ib coupes ioniennes Al ot du corinthen ancien entre autres. Voir F. PY et .ll. PY, Les amphores élrusques de Vaunage el de Villevieille, Gard, dans MFFRA, 86, 1974-1, p. 141-254.

21 Fouilte en cours d'une cabane livrant une couche unique sans imporlation. Cel habilat est situe sur le cours inferieur du Vistre, pres des etanes, dans une zone ou l'on sait, par les foulles d'll. Jrades el du groupe Painlevé, que les importations furent tres importantes des le debut du vi" s. Voir X. Guthlirz et M. PY, Note sur l'habilal prolohistorique de Port-Vielh à Aigues-Morles, Gard, dans Revue archéologique de Narbonnaise abríge RAN!, IX, 1976 sous presse;.

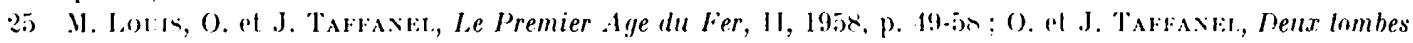

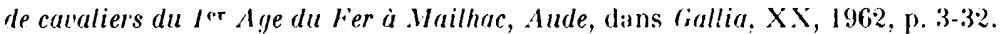

26 J. Cirry, Nécropole à incinéralion de secobre *à Ouaranle (Iléraull), dans CI.P.1, 9, 1960, p. 147-197. Dans celle nécropole il y a en fait une série de tombes ancicrines, de type mailhacien I, et une série plus récente dont

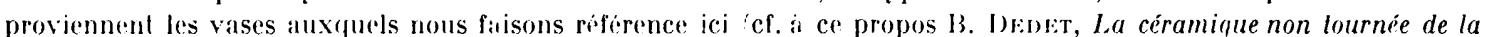

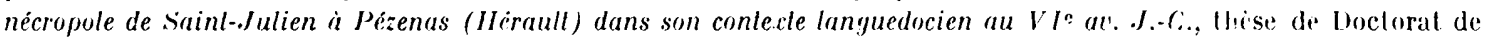
troisieme cycle, Montpollier, 1974, p. 280-282; In., Jatalion el faciès de la nécropole de Recobre à Ouaranle, Ilérault, dans $R .1 \mathrm{~N}, \mathrm{IX}, 1976$.

27 (:f. Le rapport de fouille de J. (im\%, La nécropole préromaine de siainl-Julien, commune de l'ézenas, IIéraull,

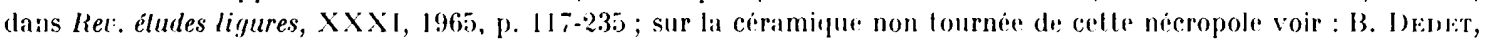
La céramique non lournée de la nécropole de Saint-Julien, op. cit.

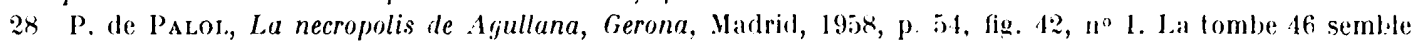
postérieure a la phase mailhacienne 1 de la nicropole.

29 Voir 13. DEnEt, La céramique non tournée de la nécropole de Sitinl-Julien, op. cil., ll le partie, chap. 6, passim.

30) J. Gindarix, L'Age du Bronze en Languedoc occidental, Roussillon, Ariége, Paris 1972, p. 314-327.

31 Voir II. Pr, I.es oppida de Vatunlege, these de troisieme cycle, Iontpellier, 1972 dactylographice, P. 405, of fi:s. $215, n^{\circ} 129$.

32 Par exemple a Recobre avec cependant une lèlı plus petite 'J. Gır, La nérropole à incinéralion de Recobre, op. cit., tombe 21). Cette tombe est ancienne. 
des coupes ioniennes $B 2$ : l'absence d'arête vive à la base du pied et l'amorce d'une tige au contact de la panse sont des traits empruntés au type B 3 et aux coupes attiques contemporaines $(560-530)^{33}$. On proposera pour cette pièce une datation dans la deuxième moitié du $\mathrm{vi}^{\mathbf{e}}$ s.

Le fragment de coupe carénée en céramique grise monochrome de forme Benoît $11 \mathrm{~A}$ est de création occidentale et plus précisément rhodanienne ${ }^{34}$. Cette forme apparaît au second quart du vie s. et semble surtout représentée dans les niveaux antérieurs à $500^{35}$.

Enfin, les fragments d'amphores massaliètes ne sauraient remonter au-delà de la fin du $v^{\mathrm{e}}{ }^{\mathrm{s}}$ s, puisqu'aucun exemplaire de ce type d'amphore n'est attesté antérieurement. La faible épaisseur des parois, l'abondance du dégraissant et la hauteur du col montrent qu'il s'agit d'amphores Benoît I appartenant au début de la série ${ }^{36}$.

\section{Groupe d'objels à chronologie lâche.}

Outre les pièces qui sont datables soit du début, soit de la fin du vi ${ }^{\mathrm{e}}$ s., la majorité du matériel de la Grotte Suspendue ne peut être typologiquement daté qu'entre ces deux extrèmes.

Parmi les objets métalliques, il y a le bracelet à boules $\mathrm{n}^{0} 99$ : cette forme de bracelet est rare en Languedoc où elle existe cependant à la fin du viI ${ }^{\mathrm{e}} \mathrm{s} \cdot{ }^{37}$ et au vi ${ }^{\mathrm{e}} \mathrm{s} .{ }^{38}$. Les armilles du type du $n^{0} 100$ sont présentes au début du vi ${ }^{\mathrm{e}}$ s. à La Liquière ${ }^{39}$ et après 550 au Grand Bassin II et à La Font-du-Coucou ${ }^{40}$. I Saint-Julien de Pézenas, ces armilles se trouvent dans une tombe datéc de la première moitié du vi ${ }^{\mathrm{e}} \mathrm{s}$. et dans plusieurs tombes du troisième quart de ce siècle ${ }^{41}$.

La céramique excisée, de son côté, est attestée en Languedoc dans des gisements

33 Sur ce type et celle date, voir (;. Valtiet el F. Vildard, Megara Hyblaea, op. cil, p. 27-29.

31 P. Ancisix, La céramique indigene modelée de Saint-Blaise, Aix-en-Provence, 1971, p. 79, montre que le's céramigues grises tournés du vo"s. imitent des formes prealablement existantes el notamment la jatte carenéce cef. ihid., pl. 23 à 26 .

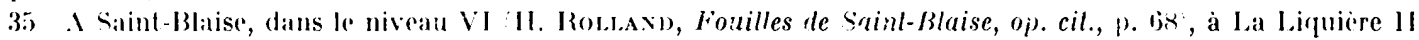
(M. PY, La céramiqne !necque de Vuunage, (iard, el sa significalion, dans LIIP.1, 20, 1971, p. 75-77 et fig. 34, nos 6, 7 et 9 , et a la Font-du-Coucou 11 (Calvisson, Gard . Celle forme est beacoup plius rare apres le vie s., par exemple à Villevieille M. PY, L'oppidum préromain de Villevieille, (iard, dans R.1., IV, 1971, p. 22:3-22.4, figr. 6 et 7; ou même absente a Vié-(ioutal B. Detot, Les niveaux proto-historiqutes de l'oppidum de Vié-Cioulal à Mons-Monteils (Gind), fouilles 1966-1968, dans RAN, VI, 1973, p. 69.

36 Ce type ancien se rencontre notamment à la Font-du-Coucou Il et dans les plus anciennes strates de l'oppidum de Vimes. Les lypes récents du ve au $\|^{2}$ s. se caractérisent par l'épaisseur des parois et un drograissant. moins serré.

37 Par exemple dans la nécropole du Grand-Bassin I M. Locis, O. el J. Tafraxld, Le Premier Age de Fer, op. cil., 11, p. 47, fig. 33 entre $\mathrm{T} 17$ et 19 .

38 Par exemple dans la nécropole de Saint-Julien an troisième quart du $7^{\mathrm{e}} \mathrm{s} .:$ tombes 48,86 et 113 inumérotation ERA 63 voir J. Giry, La nécropole préromaine de saint-Jutien. wp. cit., ?. 14i, T '08; p. 170, T 150: p. 184$1 \times 5, \mathrm{~T} 17 \%$.

39 Fond de cabane 1.5/1968 et I.7/196x; cf. M. PY, Les oppida de Vaunage, op. cit., p. 772 et fig. 393.

40 Pour le Grand-Bassin II : M. Lotis et o. el J. TaFraver, le Premier Age du Fer, op. cil., II, p. 62 : pour

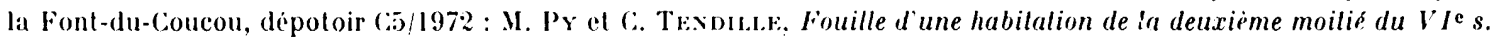
av. J.-C. sur l'oppidum de la Font-du-Coucou, commune de Calvisson, Gard, dans RAX. VIII, 1975, p. 33-65, fig. 25.

41 B. Dedet, La céramique non tournée de la nécropole de Saint-Julien, op. cit., p. 69. 
de la première moitiét2 et de la seconde moitié du vi ${ }^{\mathrm{e}} \mathrm{s}^{43}$. Il en est de même pour les autres catégories de céramique non tournée : pour la deuxième série d'urnes, à panse surhaussée et peu galbée $\left(\mathrm{n}^{\text {os }} 15 \text { à } 21\right)^{44}$; pour les urnes sans col $\left(\mathrm{n}^{0 \mathrm{~s}} 47 \text { à } 52\right)^{45}$; pour les coupes à profil arrondi convexe (n ${ }^{0 s} 53$ à 67$)^{46}$ et pour les coupelles (n ${ }^{\text {os }} 68$ à 71$)^{47}$.

La datation de tous ces documents entre dans le vi ${ }^{\mathrm{e}}$ s. avant J.-C.

\section{Interprétation.}

Étant donnés les bouleversements subis par la Grotte Suspendue après le Premier Âge du Fer, la fouille, nous l'avons vu, n'a pu préciser si l'occupation protohistorique était unique ou correspondait à plusieurs étapes. Dans ces conditions l'étude de la chronologie des objets livrés par la grotte permet en théorie d'envisager quatre hypothèses: une occupation longue et continue, débutant à la fin du viI ${ }^{\mathrm{e}}$ s. ou vers 600 et se prolongeant jusqu'à la fin du vi ${ }^{\mathrm{e}}$ s. av. J.-C. ; - une occupation plus courte de la fin du viI ${ }^{\mathrm{e}}$ s. ou des environs de 600, et une fréquentation épisodique des lieux à la fin du $\mathrm{VI}^{\mathrm{e}} \mathrm{s}$. dont rendraient compte les seuls objets datés à coup sûr de cette époque; -- une occupation également courte, mais de la fin du vi ${ }^{\mathrm{e}} \mathrm{s}$. Dans ce cas, les documents datés à coup sûr de la fin du VII ${ }^{\mathrm{e}}$ s. ou des environs de 600 seraient considérés comme des objets conservés longtemps par leur possesseur; - deux occupations d'égale importance et sans lien entre elles se seraient succédé; l'une serait de la fin du viI ${ }^{\mathrm{e}}$ s. et des alentours de 600 , l'autre de la fin du $\mathrm{vI}^{\mathrm{e}} \mathrm{s}$.

Cependant, une différence dans l'état de conservation entre les vases du groupe ancien et les documents du groupe récent nous porte à privilégier l'une de ces hypothèses. En effet, des vases sûrement anciens, beaucoup de fragments ont été retrouvés et permettent parfois de reconstituer des profils complets, alors que les témoins récents ne sont jamais représentés que par un ou quelques fragments. Il faut ajouter par ailleurs que les vases complets du troisième groupe $\left(\mathrm{n}^{\mathrm{os}} 15,53,57,68\right)$ peuvent sans aucun problème être rattachés au premier lot. En conséquence, on donnera la préférence à notre quatrième hypothèse, en considérant que : l'occupation de la fin du $v_{I_{1}}{ }^{\mathrm{s}} \mathrm{s}$. aurait eu une fin brutale (abandon? dépôt?) ainsi que l'atteste l'état de conservation des principaux vases que nous

42 A Carsac (P. Barní, J. Glinane et G. Ravcotis, Les fosses à céramiques des niveaux supérieurs de Carsuc (commune de Carcassonne) dans Bull. Soc. études scientifiques Aude, 1.XXII, 1972, p. 35-52, notamment p. 48, fig. 10 ;

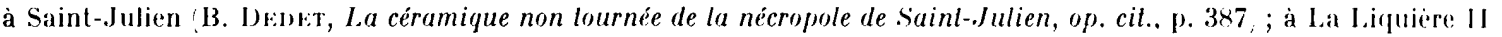
(F. PY et .I. PY, Les amphores étrusques, op. cit., p. 148 et fig. 4.

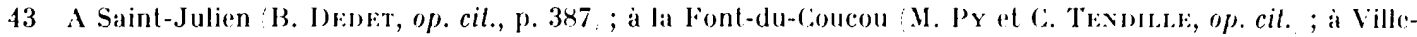

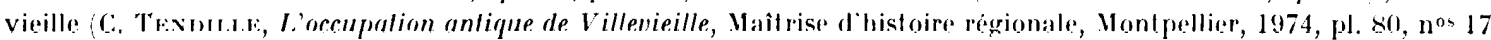

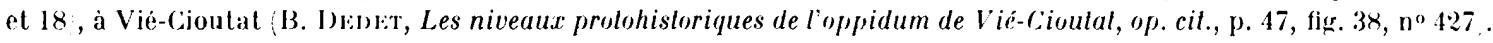

44 Ce type d’urne est notamment le plus fréquent dans toutes les strates de La Liquiere M. PY, Les oppida de Vaunage, op. cit., p. 395 et s.,

45 Vase représenté vers 600 à Bonne-Terre J. Giky, Nécropole de Bonne-Terre à Tourbes (Héraull), dans

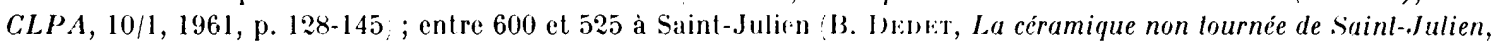
op. cit., p. 335-336; ; et entre 625 et 500 à La Liquière et à la Font-du-coucou avec un taux de fréguence qui va en diminuant (.M. Py, Les oppida de Vaunage, op. cit... Ce vase n'est guere représenté passé le ve s.

46 Forme tres fréquente des le Mailhacien l jusqu'a la fin de l'Age du Fer.

47 Ies coupelles hémisphériques à fond croux du type du no 68 existent du Mailhacien la la fin du ve s. Les exemplaires plus tardifs, beaucoup plus rares, se distinguent par des parois plus épaisses et des formes plus lourdes. 


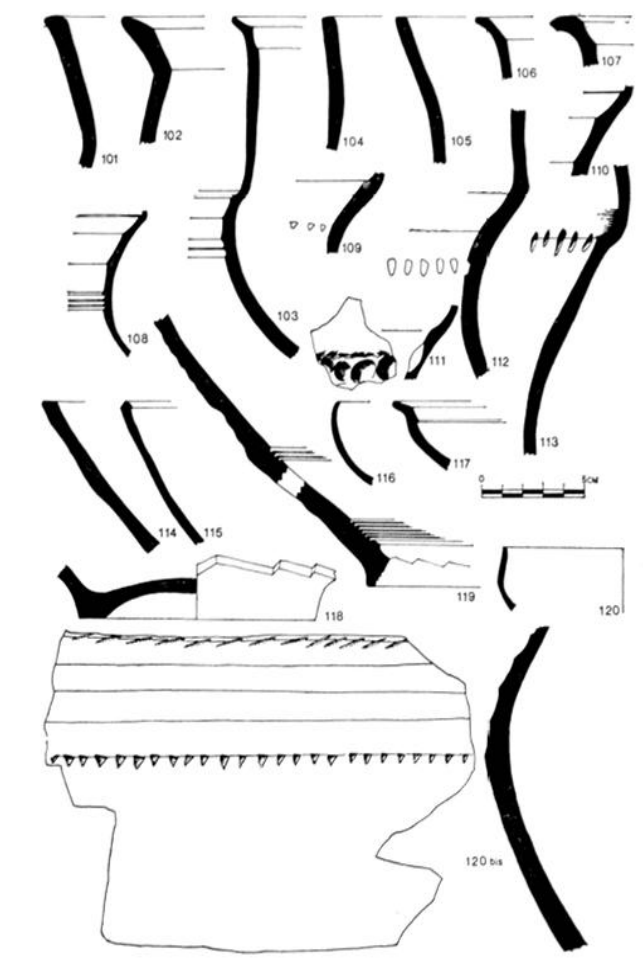

27

Grolle de la Citcrne Sainte-Anastasie . Fragments de vase's non tournés.

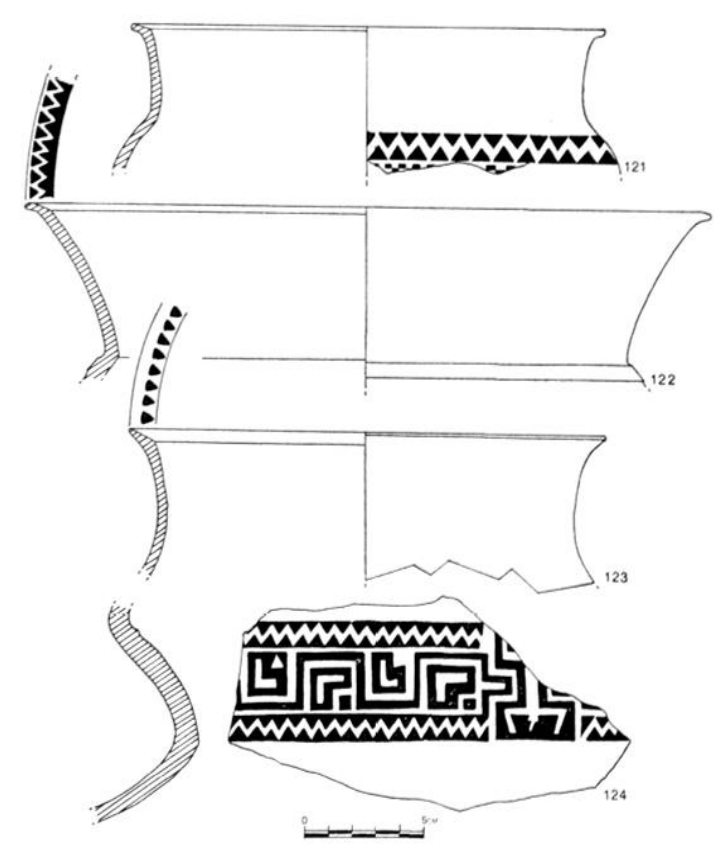

2x Balume-longue 'Jions . I rnes non tournées à décor excise.

lui attribuons; - l'occupation de la fin ${\mathrm{du} \mathrm{vi}^{\mathrm{e}}}^{\mathrm{s}}$. aurait été précédée d'un balayage dans la fosse des témoins ainsi protégés. Son déroulement aurait été normal et les restes qu'elle a laissés sont de ce fail très fragmentaires; - la réoccupation des lieux au Bas-Empire expliquerait le mélange sur les plans topographique et stratigraphique.

III. La grotte sleppexde et les gisemexts contemporans des Gorgles de Gardon

Les documents du Premier Âge du Fer livrés par la Grotte Suspendue ne sont point isolés dans les Gorges du Gardon. Én effet, cette région a été largement occupée à cette époque, comme l'attestent les trouvailles anciennes conservées au Musée d'histoire naturelle de Nîmes. Elles proviennent principalement des grottes du Canyon qui seules ont été explorées par des fouilles systématiques, les oppida, nombreux pourtant dans le secteur, n'ayant fait l'objet que de récoltes de surface ${ }^{48}$. Néanmoins, les trourailles faites en grotte ne sont accompagnées d'aucun renseignement sur les conditions de gisement et leur intérêt ne peut être que typologique. Pour cette raison nous n'étudierons que les pièces caractéristiques, en ordonnant notre inventaire et nos comparaisons par grotte, d'ouest en est des gorges.

to Ce sont les sites de Marcabum . M. Lol'1s, Carte archéologique de la (iaule romaine, VIII, Gard, 1941, p. 185) et du Castellas ,ibid., p. 187 a Sainte-Anastasie, el du Paradas de Raymonde ou camp de Castre, ibid., p. 174. 

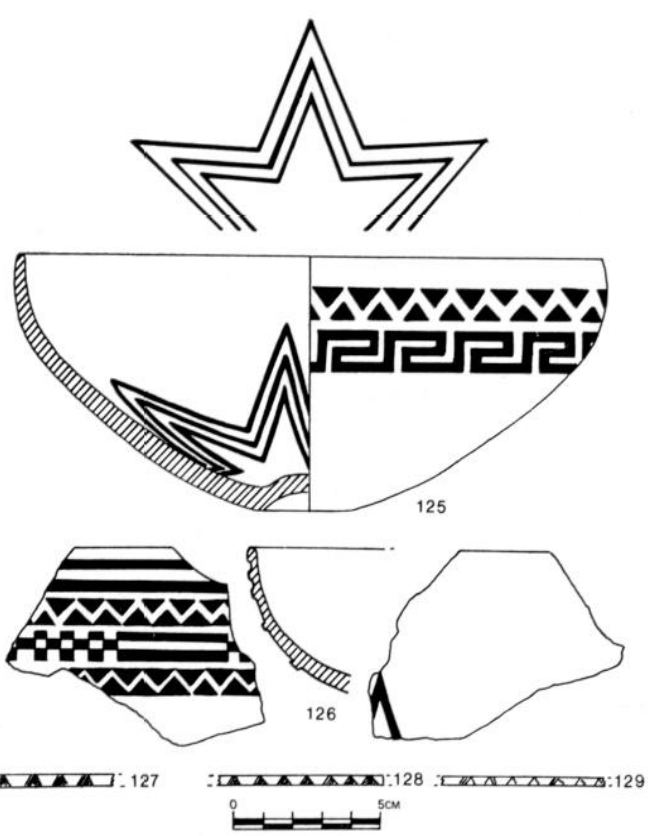

29 Baume-Longur bions . Coupes non lournés a decor rxcisé et bracelels en hronze.

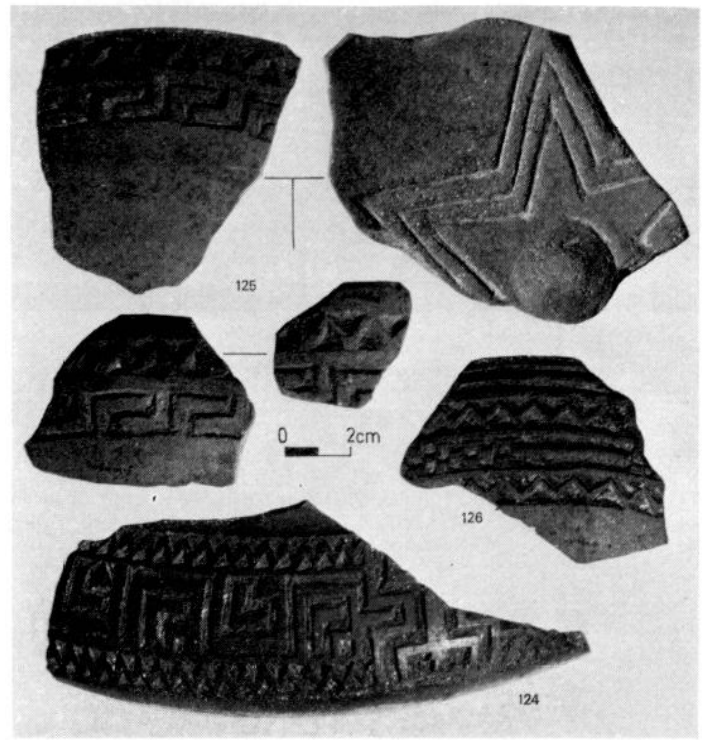

30 Bamme-Longur Dions. Vases non lourmes a décor excise.

\section{La Baume-Longue (commune de I)ions) ${ }^{49}$.}

Fig. 28, no 121 : partie supérieure d'urne excisée; bord C 11; col divergent à contact col-panse adouri. Le décor est situé sous le contact col-panse. el il n'en reste qu'une double série de triangles emboités et excisés, dégageant une ligne brisée champlevée. Cette frise surmonte une zone en damiers. Le dégraissant est abondant et formé de calcaire broyé. fin et moyen. hien calibré et bien réparti. Les surfaces extérieure et intérieure ont un lissage fini (état $n^{0} 2$ ).

Fïg. 28, no 122 : partie supérieure d'urne excisée; bord C 11, col divergent a contact col-panse anguleux; le décor est situé à l'intérieur sous le bord. Il s'agit d'une ligrne brisée champlevée. Le dégraissant est abondant, fin el moyen; il est formé d'inclusions mal calibrées mais bien réparties de calcaire broyé. Aménagement des surfaces : à l'exlérieur. $n^{0} 1$; à l'intérieur, $n^{0} 2$.

Fig. 28, no 12:3 : col d'urne à décor impressionné; bord C 19. Le décor est situé à l'intérieur sous le bord et formé de triangles impressionnés. Dégraissint de calcaire broyé el de calcite. fin et moyen, peu abondant. Aménagement des surfaces; no 2 partoul.

Fig. 28 et $30, n^{\circ} 124$ : fragment de panse d'urne. du type de la premirire série d'urnes de la Grotte suspendue, à col haut et pied has. I.a partie supérieure de la panse est décorée d'une frise complexe qui s'interrompt pour laisser place it une liguration anthropomorphe aux altributs masculins netlement indiqués. Dégraissant abondant de calcaire broyé, fin et moyen, bien réparti. Aménagement des surfaces : $n^{0} 1$ à l'extérieur, $n^{0} 3$ à l'intérieur.

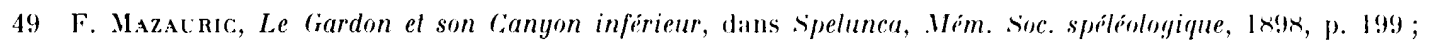

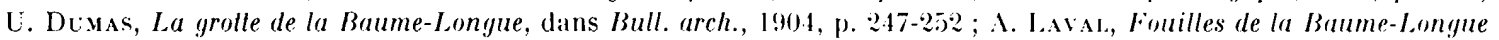

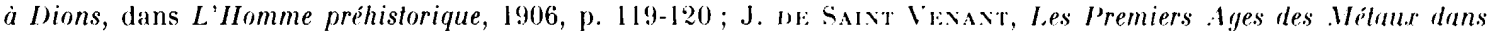

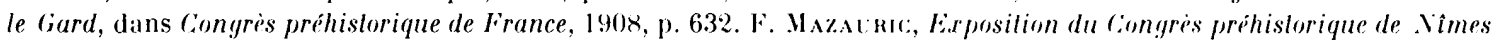
dans L'Ilomme préhistorique, 1911 , p. 269 ; 11., C. r. du Congrès préhistorique de France, 1911, p. 656 ; L. I)cuas, Des temps intermédiaires entre la pierre polie el l'ópoque romaine, dans Bull. Soc. préhistorique française abrégé : BSPF ,

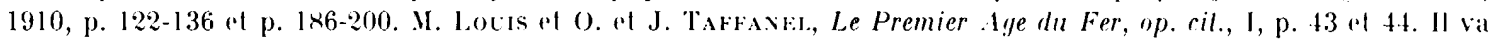
de soi que la bibliographie que nous donnons de chaque grotte se limite à l'essentiel. 
Fig. 29 et :30. no 125: quatre fragments d'une roupe dont le profil est complet ${ }^{50}$ : forme 422 ; bord IO 1 ; fond $21 \mathrm{~A}$; rapport : 37 . Le décor se silue à deux endroits différents : à l'intérieur, autour du fond. une triple étoile excisée; a l'extérieur. hande horizontale formée d'une ligne brisée champlevée surmontant une grecque excisée. Le dégraissant. trìs abondant, est formé de calcaire broyé fin et moyen. Aménagement des surfaces : intérieur $n^{0} 1$; extérieur $n^{\circ} 2$.

Fig. $29 \mathrm{el} 30 . \mathrm{n}^{\circ} 126$ : fragment de coupe hémisphérique; bord F() 1. Le décor est situé à l'intérieur el à l'exlérieur. A l'inlérieur. il s'agit d'une branche d'étoile excisée. A l'extérieur. c'est une large bande composée de haut en bas de deux lignes droites excisées, une ligne brisée champlevée, d'une alternance de damiers el de segments de droites et pour finir. une nouvelle ligne brisée champlevée. Le dégraissint, abondant, fin. hien calibré et bien réparti. est formé de calraire el de calcite broyés et de micia.

[ïin. 29, nos 127 a 129 : plusieurs bracelets-armilles en bronze, de section quadrangulaire. dont certains sont décorés sur la face externe d'incisions fines formant des lignes brisées et des triangles hachurés.

Ge lot homogene de vases excisés el de bronzes appelle des comparaisons avec la Grotte suspendue et d'autres gisements. Les cols d'urnes nos 121 à 123 et les coupes nos 125) et 126 sont tout a fail semblables par leur forme et leur décor à des vases excisés de la Grotte suspendue (ci-dessus. nos 81 a 86 ). On remarque par ailleurs que la forme de l'urne $n^{0} 124$ appartient au type de la premiere série d'urnes de la Cirotle suspendue. Les molifs des décors excisés sont connus en Languedor. particulierement dans les nécropoles tumulaires de l'Ilérault et du Gard, à La Liquiere et à saint-Julien de Pézenas's . Ie motif anthropomorphe a une forme ici légèrement différente des ligurations toujours identiques que l'on rencontre sur les vases des tumulus et dans la grotte Nicolas (voir ci-apris. nos 1:31-132). Les bracelets-armilles diffirent de l'exemplaire de la Grotte suspendue par leur section rectangulaire et la présence d'un décor. Ce type est bien connu dans plusieurs gisements languedociens du ${ }^{2}{ }^{\mathrm{e}}$ s.. par exemple dans la tombe 15 du Grand-Bassin II à Mailhac ${ }^{52}$. a Saint-Julien de Przenas ${ }^{53}$ el dans les tombes 3 el 4 de la nécropole de la Berrerie-Hermet à Galvisson ${ }^{54}$.

\section{Cirolle de la Citerne (commune de Sainte-Anastasie $)^{55}$,}

Le Musée d'histoire naturelle de Nìmes conserve plusieurs caisses de mohilier. essentiellement de la céramique, provenant des fouilles conduites par M. Louis. Nous donnons en illustration les formes les plus typiques contenues dans ce bot (fig. 27). ()n y trouve tout d'abord des urnes a panse très galbee donl la plupart portent des cannelures larges et horizontales. parfois ansociées a des rangées d'impressions ou de coups incisés ( $\mathrm{n}^{0 \mathrm{~s}}$ 103. 108. 109. 110. 112 et $120 \mathrm{bis}$ ). Quelques panses. décorées d'impressions ou de cordons impressionnés, ne portent pas de cannelures (nos 111 et 113). Les bords d'urnes sont de types $123\left(\mathrm{n}^{\circ} 107\right)$. C $12\left(\mathrm{n}^{0} 106\right)$. C 21 ( $\left.\mathrm{n}^{\circ} 103\right)$. C $29\left(\mathrm{n}^{0} 102\right)$, I) $122\left(\mathrm{n}^{0} 101\right)$

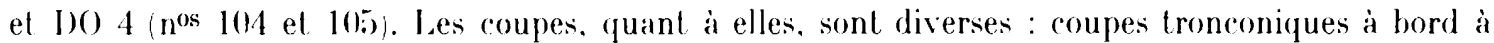
méplat. dont un bord C 21 ( $\mathrm{n}^{\text {os }} 117$ et 119 ); coupes à panse arrondie-convexe, équipées de bords EO $4\left(\mathrm{n}^{\circ} 114\right)$ et $\left.\mathrm{E} 16\right)\left(\mathrm{n}^{0} 115\right)$, coupe hémisphérique (bord 10$\left.) 1 ; \mathrm{n}^{0} 116\right)$ et carénée (bord HO 1 ; $\mathrm{n}^{\circ}$ 120). On remarquera que les urnes ont des surfaces aménagées de facon identique pour le col

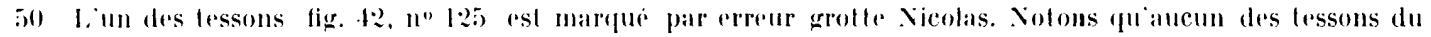
Musere d'histoire naturelle de Nimes me porte de numbro dimventaire.

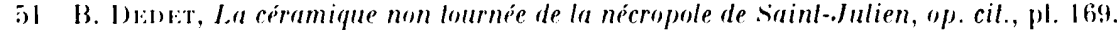

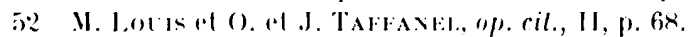

5.3 J. Gins. Ia necropole préromaine de saint-,Julien, op. cit., p. 2:37.

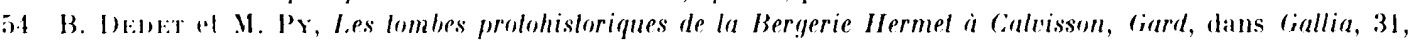
$1973,1) .37-59 !$.

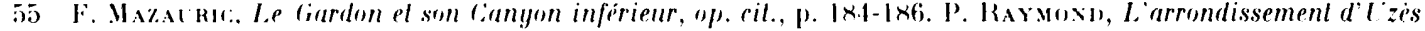

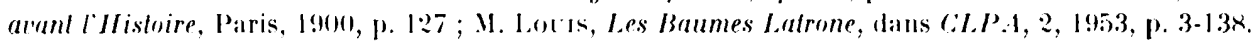



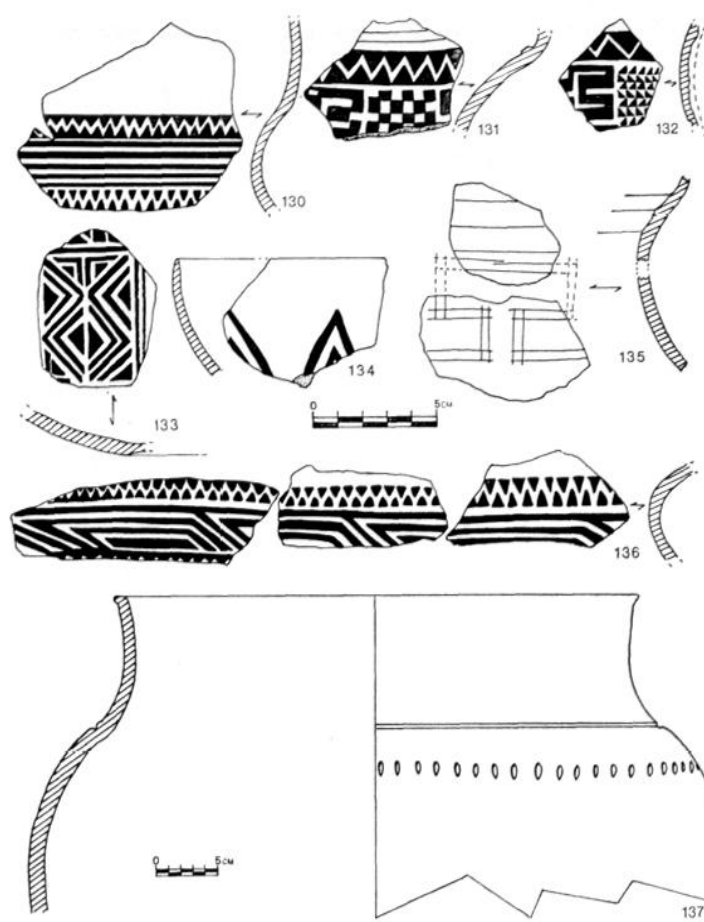

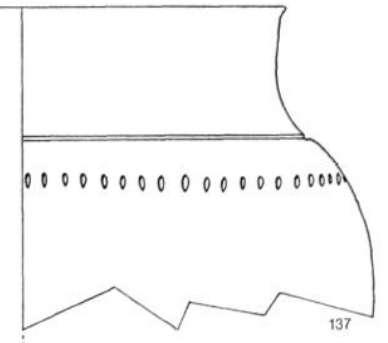

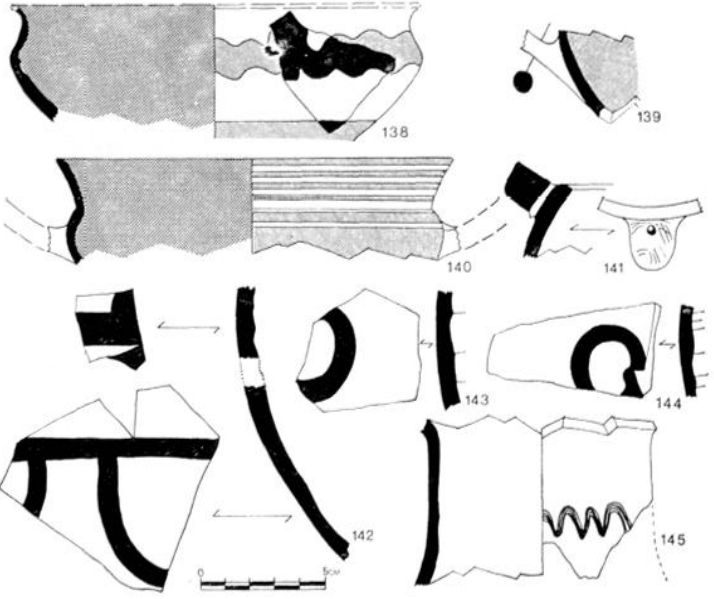

32 Grotte Saint-Véredeme Sanilhac. Céramique grecefue deccident el ihero-languedocienne no $^{\circ} 141$.

31 Grotfo Nicolas "Sainte-Anastasie: Céramique non lournee.

et la panse, c'est-à-dire une fois polissage $\left(n^{0} 110\right)$ et les autres fois lissage fini. Pour les coupes, l'aménagement des surfaces est étroitement lié à la forme : ainsi les coupes tronconiques ont une surface intérieure polie, l'extérieur étant non aménagé $\left(\mathrm{n}^{\mathrm{O}} \mathrm{s} 117-119\right)$, alors que les coupes à profil arrondi-convexe et hémisphérique ont un égal traitement des parois exlérieure et intérieure (lissage fini). I.e dégraissant est uniformément composé de calcaire et de calcite broyés, auquels s'ajoute parfois du mica.

Ces vases présentent tous les caractires (formes, décors, aménagements des surfaces) de la céramique du Bronze final III 3 du Languedoc oriental, si ce n'est les décors caracléristiques du Mailhacien I. A ce titre, on comparera le mobilier de la grotle de la Citerne aux documents qu'a livré l'oppidum de Gauto-Fracho, à Bouquet (Gard) ${ }^{56}$.

3. Grolle Nicolas (commune de Sainte-Anastasie) ${ }^{57}$.

Fig. 31, no 130 : panse et col d'urne excisée à contact col-panse adouci. Le décor situé sur la panse est composé de lignes horizontales excisées encadrées par deux lignes brisées champlevées. Dégraissant abondant, fin et moyen, de calcaire et calcite broyés, ainsi que de mica. Aménagement des surfaces : à l'extérieur et à l'intérieur, no 2 partout.

Fig. 31, no 131 : fragrment de panse d'urne à contact col-panse anguleux, orné de cannelures horizontales et d'un décor excisé composé d'une ligne brisée champlevée surmontant des damiers

56 Voir B. Dever, Loppidum de Gaulo-Fracho à Bouquet, Giard, dans RAN, VIII, 1975, p. 1-26; notons que toutes ces formes se rencontrent également dans fes sites mailhaciens I, ot notamment dans la région, a liorpue-de-Viou Saint-I)ionisy, a la Bergerie-Hermel Calvisson, a Triple Levere Beaucaire ou an Grand-Ranc Boucoiran .

57 L. Demas, La grolle Nicolas, commune de Sainle-Anastasie, dans Rev. ec. anlhr. Paris, 1905), p. 118-124;

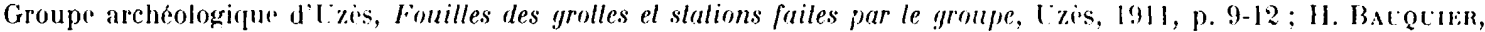
I'résentation d'une slatuelle el de fragments de polerie provenant de la grolle Nicolas, dans lihodania, n" 2.10 , Grenoble, 1920, p. 14 ; .I. Locis et O. et J. Taffaxil, Le Premier Age du Fer, op. cil., I, p. 42-13. 
alternés avec un molif peut-être anthropomorphe. Dégraissant abondant, fin et moyen, de calcaire broyé. Aménagement des surfaces : à l'intérieur $n^{0} 2$ et à l'extérieur $n^{0} 3$.

Fig. 31, no 132 : fragment de panse d'urne excisée, décorée d'une ligne brisée champlevée surmontant une zone de triangles excisés et un motif anthropomorphe. Dégraissant abondant et fin de calcaire el calcile brovés. bien réparti. Aménagement des surfaces : a l'extérieur no 2.

Fig. 31, no 133: : fragment de coupe hémisphérique à fond creux (forme $21 \mathrm{~A}$ ), décoré intérieurement de triangles et de lignes brisées emboîtées. Dégraissant abondant et très fin de calcaire et de mica. Aménagement des surfaces : $\mathrm{n}^{0} 2$ partout.

Fig. 31, no 134 : bord Fo 9 de coupe hémisphérique décorée à 1 intérieur d'une étoile excisée. Dégraissant abondant, composé de calcaire et calcite broyés et de mica, de taille fine. Aménagement des surfaces, à l'extérieur comme à l'intérieur, no 1.

Fig. 31, n 135 : fragments de panse d'urne décorée de deux cannelures horizontales surmontant un motif incisé en double trait. probablement un méandre symétrique. Dégraissant mal calibré, fin et moyen, de calcaire et calcite broyés et de mica. Aménagement des surfaces : no 2 partout.

Fig. $31, n^{0} 136$ : trois fragments d'urne à panse très galbée et décorée d'une frise de trapèzes emboîtés encadrée par deux lignnes brisées champlevées.

Fig. 31, no 137 : partie supérieure d'urne à col convergent et contact col-panse anguleux; bord $\mathrm{CO}$ 4. Le décor, sur l'épaule, consiste en une rangée horizontale d'impressions ovalaires. IDégraissant forme de calcaire broyé de dimension moyenne, et de rares inclusions roulées de quartz. La surface est aménagée de façon identique partout (lissage ébauché).

Nous retrouvons dans ce lot des vases excisés très comparables par le décor comme par les formes à ceux de la Baume-Longue et de la Grotte Suspendue. Le décor incisé du vase $\mathrm{n}^{0} \mathbf{1 3 5}$, héritier d'une tradition remontant au Bronze final III $A^{58}$, se retrouve aussi à La Liquière jusqu'au début du vi ${ }^{\mathrm{e}}$ s. $^{59}$. Pour sa part, l'urne de grandes dimensions no 137 est comparable à un exemplaire de la Font-du-Goucou daté de la fin du vi ${ }^{\mathrm{e}} \mathbf{s}^{60}$.

\section{Grolle Saint-Joseph (commune de Sainte-Anastasie) ${ }^{61}$.}

Fig. 33, no 146 : partie supérieure d'une urne à col haut et panse très galbée; bord C 21; décor sur l'épaule de quatre cannelures horizontales. Dégraissant abondant de calcaire et calcite broyés. Aménagement des surfaces : à l'extérieur $n^{0} 1$ partout, à l'intérieur $n^{0} 3$.

Fig. 33, no 147 : partie supérieure de coupe à profil arrondi-convexe: bord IO 1.

Ce sont deux formes de vases bien représentées dans la Grotte Suspendue.

5. Baume de Saint-Vérédème (commune de Sanilhac) ${ }^{62}$.

Cetle grotte a livré notamment un intéressant lot de fragments de vases tournés de type grec d'Occident.

5x J. Bot dol, J. Arval el A. Soltor, La céramique incisée à méandres symélriques du Pont du I)iable (Iléraull),

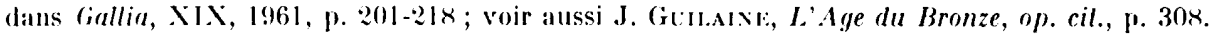

59 F. PY ol .I. Pr, Les amphores élrusques, op. cil., p. 207, fig. 2, n" 6.

60) Itidl., p. 210, fig. 5), n"11.

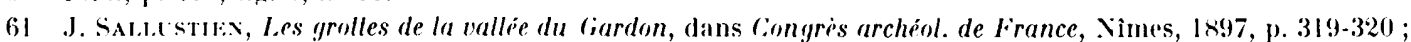

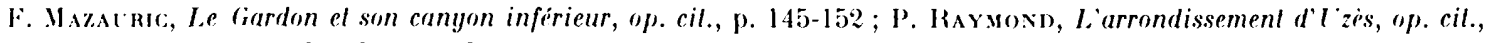
p. 197-200; M. Locss, Les Baumes Latrone, op. cit.

62 P. Raymoxn, L'arrondissement d'lzis, op. cil., passim: J. Saldcstrix, La grolte nélithique de Saint-

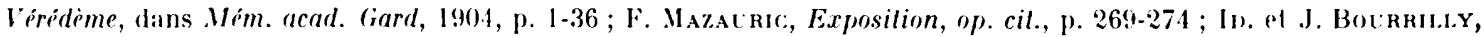
Fouille de la Baume saint-Vérédème, premiere campagne 1912, dans Assoc. française pour l'Avancement des sciences, Tunis, 1913, p. 412-117; A. Joc 1.1., (Unelques aspects archéologiques du Languedoc médilerranéen, dans Rev. arch., 1920,

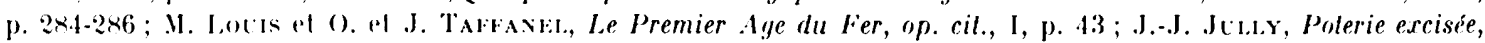
polerie peinle "de style méditerranéen "el poterie an graphile à la grolle Saint-Vérédème, Sianilhac (Gard), dans BSPF, I.VIII, 1961. p. 332-3.11. Trois tessons peints sont publiés dans t: Lacipaxd, La céramique "pseudo-ionienne "dans

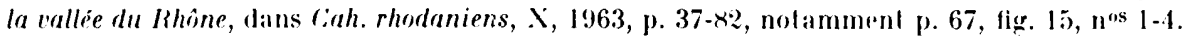




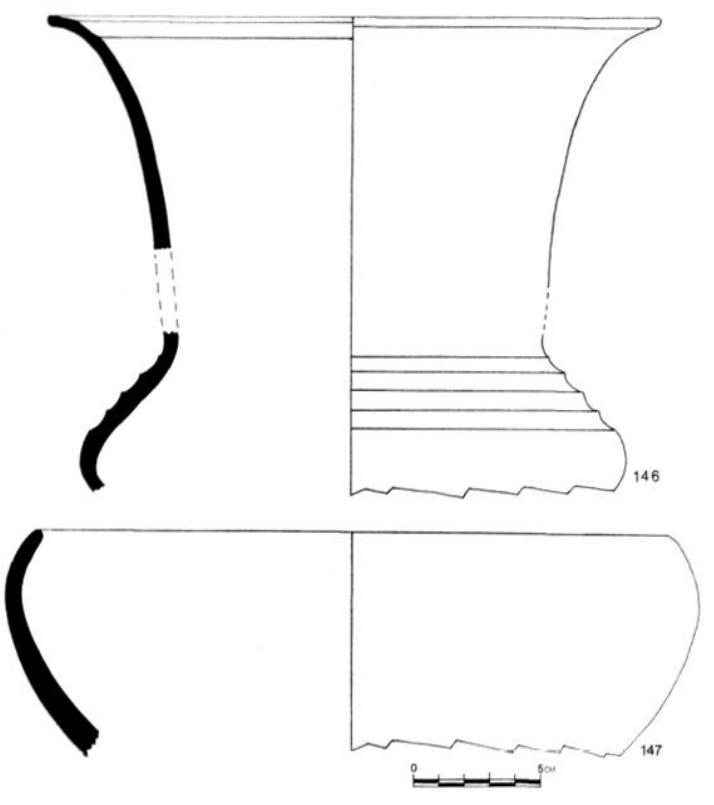

33 Grotte Saint-Joseph Sainte-Anastasie . Ceramique non tournée.

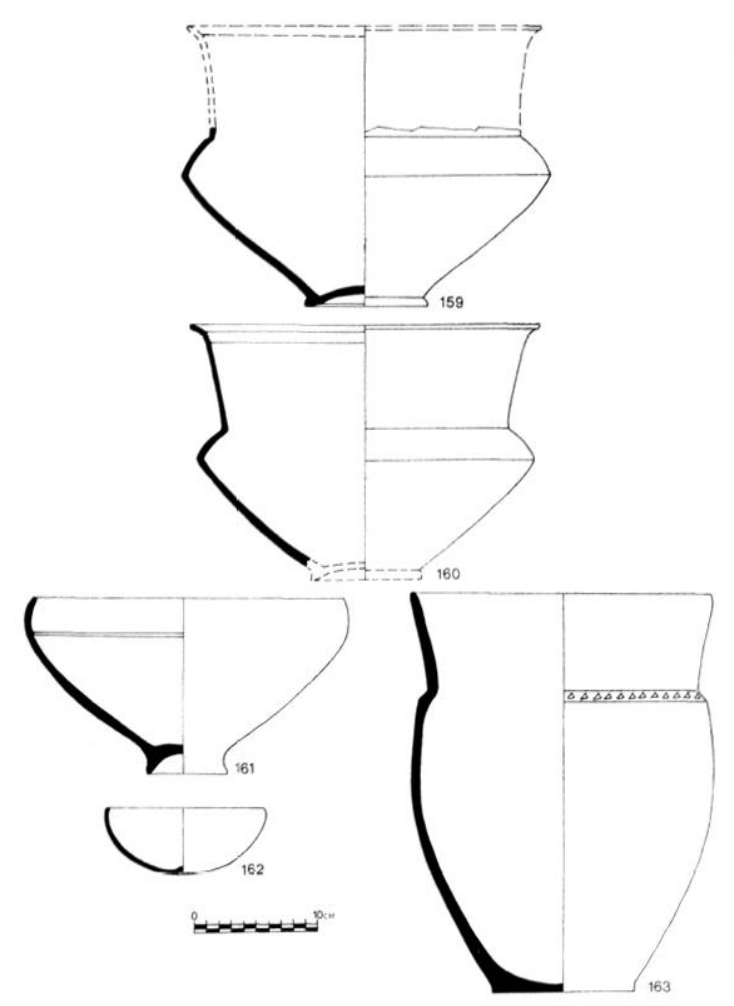

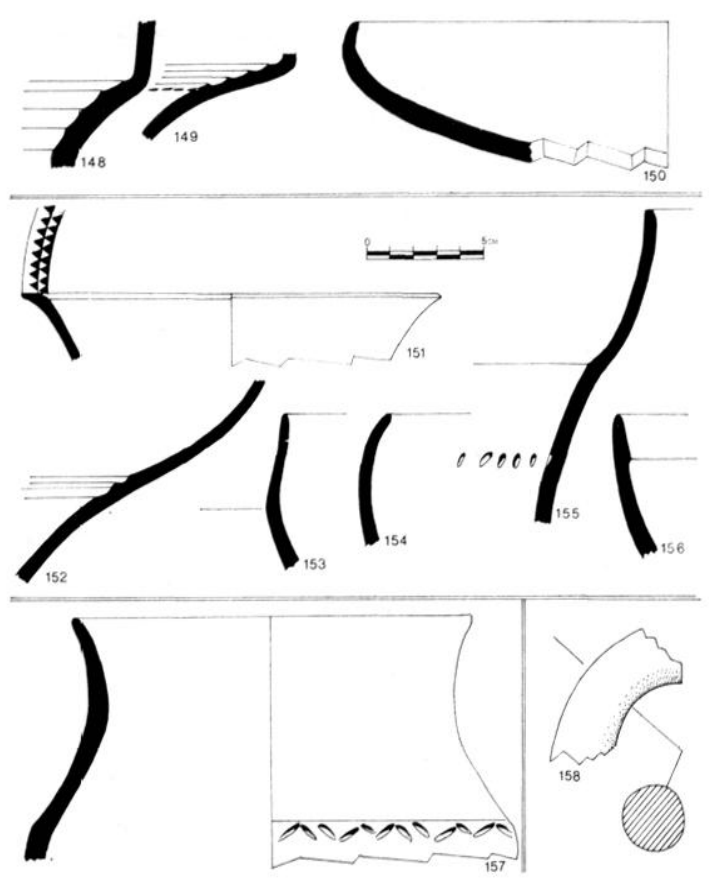

34 148-150: grotte de l'Eounas Collias, ; 151-156: grotte de la Fraissiniere Collias ; 157 : grotte de Pàques Collias, ; 158 : grotte de la Salpétriere Remoulins.

35) Vases non tournés de comparaison: 159 : habitat de Port-Vielh Aiques-1lorles, Gard ; 160-163: oppidum de La Liquiere Calvisson, Gard phase la du sile!.

Fig. 32, no 138 : fragment de vasque d'une coupe profonde et carénée à lèvre déversée. Pâte jaune clair, très dure et serrée; dégraissant : poussière de mica blanc. Surface mal lissée à l'intérieur et l'extérieur. Peinture violine, résistante el épaisse, luisante à l'intérieur, et mate à l'extérieur. Décor : onde molle surmontant une bande horizontale. 
Fig. 32. no 139 : fragment de coupe profonde à anse relevée en céramique subgéométrique rhodanienne: pàte jaune orre. dure. homogine; dégraissant de fine poussière de mica; peinture mince, effacée. de couleur brun rouge.

Fig. 32. $n^{0} 1.40$ : fragment de coupe a livre. a anse relevée. en céramique pseudo-ionienne ${ }^{63}$. Pàte blanchàtre. dure et lissée. Dégraisiant tres fin de mica blane et de petils grains de calcaire. Peinlure lissée épaisse el ecaillée. appliguée directement sur la paile de couleur rouge a brun : bandes horizonlales a lextérieur. intérieur entirement peint.

Fïg. 32. $n^{0} 1.11$ : fragment de bord de vase à oreillette perforée de lype ibéro-languedocien. Pate jaune heige. fine. homogene ef risistante: pas de dégraissanl visible; peinture brun ocre a l'extérieur. mince. transparente et assez résistante.

Fig. 32, no 142: deux fragments de la panse d'une oenorhoe subqéométrique rhodanienne; pàte jaune orre à gris ocre, brùlée secondairement. leuilletée. peu homogène el éclatée a l'intérieur. stries de lournage à l'extérieur; dégraissant formé de poussiore de mical blanc et de grosses inclusions calcaires; peinture brun rouge eflacée.

Fig. 32. nos 143 et 144 : deux fragments de la panse d'une oenochó subgéométrique rhodanienne; pàte jaune clair, dure. homogrine et non rayahle à l'ongle; dégraissant de fine poussibre de mica; surface extérieure bien lissie. Peinture noire, mince. mate et résistante.

Fï. 32, $n^{0} 145$ : col d'atiquiere de forme Benoit 15, en céramique grise monochrome d'occident ${ }^{64}$. Pâte gris clair, assez dure a dénraissant fin de calcaire et de micia. Linduit gris vert à l'extérieur. gris noir à l'intérieur. peu épais el eflaré. Décor : onde incisée au peigne. située au milieu du col.

On retrouve dans ce mobilier des catégories représentées par quelques documents dans la Grotle suspendue froupe a livre et céramique grise). Ces tessons appartiennent à trois styles bien connus alentour: les coupes a livre pseudo-ioniennes sont typiques de la fin du vi $\mathrm{r}^{\mathrm{s}}$ et du re $\mathrm{s}$. en Languedoc oriental el dans la vallée du Rhòne65; le style subgéométrique rhodanien apparaît abondamment dans la mème région a la mème époque ${ }^{66}$. Par conlre, le fragment du vase à oreillette perforée $n^{0} 141$ est le seul connu de ce lype en I.anguedoc oriental. alors que cetle forme est fréquente en Lanquedoc occidental ${ }^{67}$.

\section{Cirolle de l'Eounas (commune de Colliasis ${ }^{68}$.}

De celte grotte. ne sont conservés au Musée d'histoire naturelle de Nimes que deux épaulements d'urnes à décor cannelé el impressionné (figr. $34 . n^{\text {os }} 148$ et 149), et un fragment de coupe à profil arrondi-convexe, équipée d'un bord I0) 1 (lig. 34. $\mathrm{n}^{\circ}$ lin)

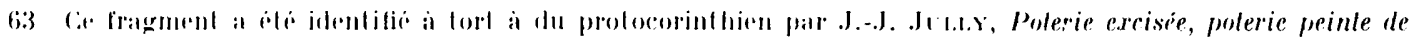

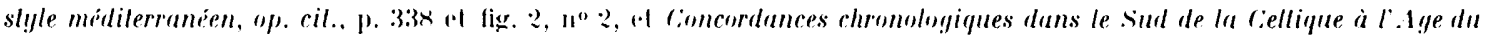

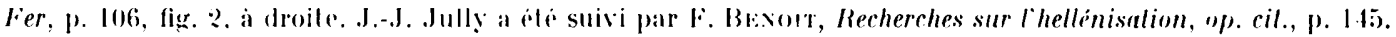

64 F. Bнхот, op. cit., p. 162 et pl. $24, \mathrm{n}^{\circ} 7$.

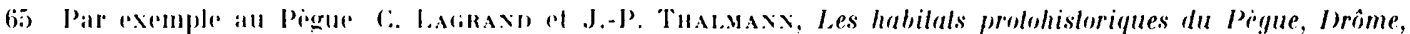

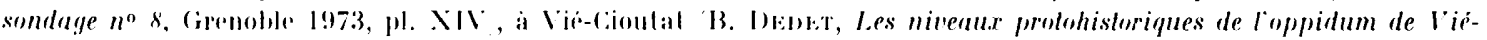

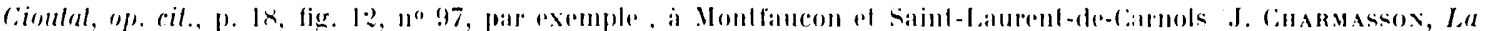

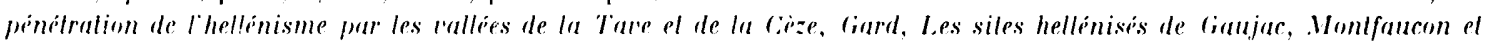

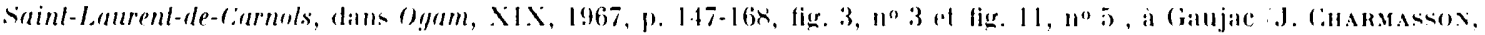

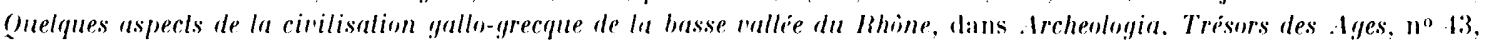

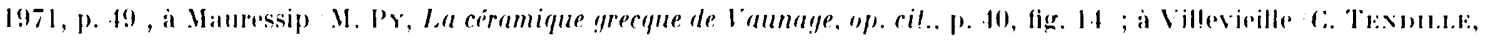

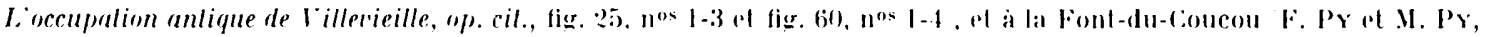
Les amphores atrusques de laumage, op. cil., fig. $5, \mathrm{n}^{\circ} 6$, etc.

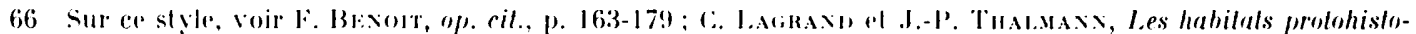

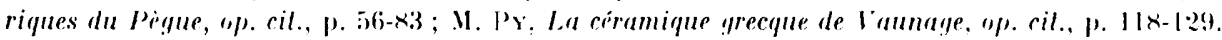

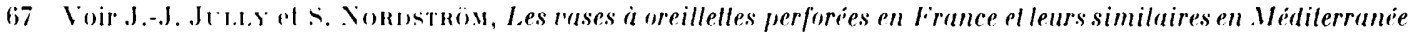
occidentale, dans Architon de Prehistoria Lenantina. XI, 1966, p. 99-1:21.

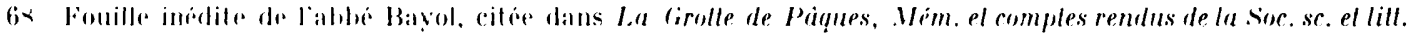
d.Alis, Xl. NII, 1935. 


\section{Grotle de la Fraissinière (commune de Collias) ${ }^{69}$.}

Fig. 34. no 151 : bord d'urne de forme G 14; décor excisé à l'intérieur sous le bord : deux séries superposées de triangles excisés. Dégraissant de calcaire et de calcite broyés. Aménagement des surfaces : $n^{\circ} 2$ à l'extérieur, $n^{\circ} 1$ à l'intérieur.

Fiğ. 34, no 152 : épaulement d'urne décorée de deux cannelures. I)égraissant de calcaire et calcite broyés. Aménagement des surfaces à l'extérieur : $\mathrm{n}^{\circ} 2$ sur le col, $\mathrm{n}^{\circ} 3$ sur la panse.

Fig. 34, no 15:3 : bord de coupe carénée, de forme $\mathbf{G 0} 1$. Dégraissant de calcaire et calcite broyés et de quelques inclusions roulées de quarl. Aménagement des surfaces : no 2 partout.

Fïg. 34, no 154 : bord 101 de coupe à profil arrondi-convexe. I)égraissant de calcaire et calcite broyés. Éral aménagement des surfaces à l'extérieur et à l'intérieur (lissagre fini).

Fig. 34, no 15) : parlie supérieure d'urne à col convergent et contact col-panse anguleux; panse peu galbée; bord GO) 1. Décor à la partie supérieure de la panse, formé d'une rangée horizontale d'impressions ovalaires. Dégraissant de calcaire et calcile broyés. Aménagement des surfaces, à l'extérieur, lissage fini sur le col et la panse.

Fig. 34, no 156 : bord de coupe à profil extérieur arrondi-convexe, de forme FO 9, et souligné à l'intérieur par un ressaut. Décraissant de calcaire et calcite broyés. Aménagement des surfaces : no 1 partout.

Ces témoins céramiques sont tout à fait semblables à ceux qu'a livrés la Grotte Suspendue, en particulier le bord d'urne excisée $n^{\circ} 151$ et le bord de coupe a ressaut interne $n^{\circ}$ 156.

\section{8. (irolle de Pâques (commune de Gollias) ${ }^{70}$.}

De cette grotte provient la partie supérieure d'une urne à col convergent à contact col-panse anguleux; bord CO 1; décor sur l'épaule de coups incisés en chevrons (fig. 34, no 157).

Par comparaison avec d'autres trouvailles du Gard, on datera celle urne de la fin du $\mathrm{VI}^{\mathrm{e}} \mathrm{s}$. ou du ves. av. J.-C. ${ }^{71}$.

\section{Grolte de la Salpétrière (commune de Remoulinsit?.}

Dans les collections du Musée d'histoire naturelle de Nîmes, se trouve une anse d'amphore étrusque provenant des fouilles Bayol à la Salpétrière. Ce témoin (fig. 34, no 158) est le seul de son époque relevé dans la grotte. $\Lambda$ son propos, on soulignera l'absence d'amphores étrusques dans les autres grotles du Gardon, et en particulier dans la Grolte suspendue dont tout le mobilier a été conservé. Or, la Grotle Suspendue, nous l'avons vu, a été occupée à l'époque où précisément les sites de plein air de la région de Nîmes livrent un trìs grand nombre de ces amphores ${ }^{73}$. On s'en étonnera d'autant plus que des tessons d'amphores étrusques ont été trouvés dans les gorges du Gardon. sur les oppida de Marbacum (Sainte-Anastasie) ${ }^{74}$ et du I'aradas de Raymonde (Sanilhac) ${ }^{75}$.

69 Fouille incilile de labbe Bavol.

70) P. (A)

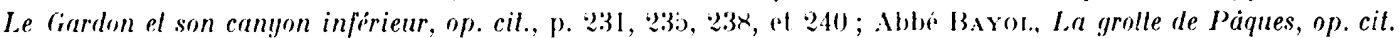

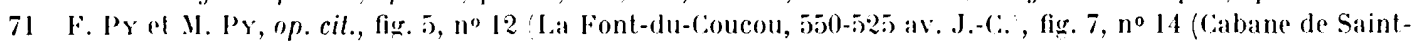

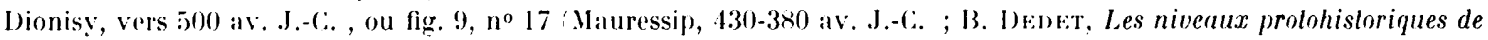
loppidum de Vis-Cioulal, op. cit., p. 32., fig. 25, no $226525-300$ av. J.-(.. .

72 P. Cazatis De Foxdot:ce, Recherches géologica-archéologiques dans la vallée inférieure du Gardon, dans Mém. acad. Gard, 1871, p. 516-540 ; In., L'homme dans la vallée inférieure du fiardon, op. cil., p. 37-56. J. SAI.t.sTIEN, Le Gard préhistorique, quelques grolles des bords du Gardon aux environs d' l'zes, dans Revue du Midi, $1898, \mathrm{p} .80-90$ ( $\mathrm{t}$ 316-328. F. BAscot1, Essai historique sur le châleau de Saint-Privat, Nìmes, 1911, p. 19-28.

73 F. PY al . I. PY, op. cil.

74 A. RoвњRT, Les oppida du Ciard, dans Cellicum, XII, 1965 , p. 220 ed prospection persommelle.

7i) Touvaille offectué dans un sondage en cours. 
L'étude conjointe du gisement de la Grotte Suspendue et des documents provenant des sites voisins des gorges, permet de définir les caractères de l'occupation d'une région naturelle très originale, et de la replacer dans son contexte régional.

Bien que les témoins du Bronze final III ne soient pas absents des grottes des gorges, comme le montre le gisement de la Citerne, et peut-être d'autres encore que l'on a rattachés à cette époque (grotte d'En T'ourieire et grotte Amont de Castelviel, commune de SainteAnastasie $)^{76}$, notre enquête dénote une plus grande quantité d'objets attribuables aux époques représentées dans la (irotte Suspendue (fin $\mathrm{vil}_{-\mathrm{VI}^{\mathrm{e}}}^{\mathrm{e}}$ s. av. J.-C.). Les documents trouvés dans les fouilles ancirnnes sont actuellement sans contexte et ne peuvent être classés que par la typologie, mais il est indéniable qu'ils forment avec les trouvailles récentes un ensemble homogène.

Le mobilier de la Baume-Longue et des grottes Nicolas, Saint-Joseph, de l'Eounas et Fraissinière, conservé au Musée d'histoire naturelle de Nîmes, ne représente certainement qu'une partie choisie des objets livrés par ces gisements. Il n'en reste pas moins que les identités avec la Grotte Suspendue sont frappantes, aussi bien pour les formes que pour les décors de la céramique. En effet, les urnes à col haut et panse galbée se retrouvent à la Baume-Longue (no 124) et à la grotte Saint-Joseph $\left(n^{0} 146\right)$; la forme des urnes excisées à col divergent existe aussi à la Baume-Longue (nos 121 à 123), à la grotte Nicolas (nos 130, 131 et 136$)$ et à la Fraissinière $\left(\mathrm{n}^{0} 151\right)$; les coupes hémisphériques à décor excisé sont

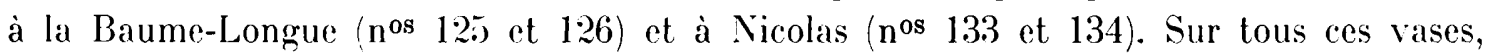
composition et thèmes décoratifs sont souvent analogues. Par aillcurs, les catégories de céramique grecque d'Occident de la Grotte Suspendue sont présentes à Saint-Vérédème.

Cet ensemble peut être comparé à d'autres gisements du Languedoc oriental. Pour la fin du $v_{I I}{ }^{e}$ s. les deux seuls sites connus dans cette région, La Liquière I et Port-Vielh, ont livé des vases semblables aux documents contemporains trouvés dans les gorges du Gardon. Pour le $v^{\mathrm{e}}$ s., on trouve aussi de nombreuses comparaisons sur les oppida de Ia Liquière II, de la Font-du-Coucou, de Villevieille et de Vié-Cioutat, comme nous l'avons montré. Tout ceci indique bien que les trouvailles des gorges du Gardon s'intègrent parfaitement dans leur contexte régional.

Lne mention particulière doit être faite pour le skyphos de style rhodien de la Grotte Suspendue, qui apporte un élément supplémentaire au problème des importations grecques archaïques, antérieures à la fondation de Harseille ou contemporaines de celle-cin. On doit, en effet, mettre cette pièce sur le mème plan que les coupes ioniennes A 1 de SaintBlaise, La Couronne et La Liquière, les fragments de protocorinthien et de corinthien ancien de Saint-Blaise, La Couronne, Antibes (?), Sainte-Anne-d'Évenos, grotte Ci de

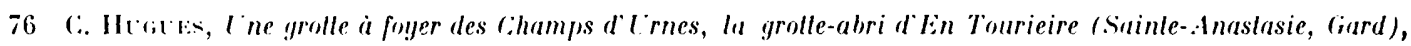
dans Cahiers rhodaniens, $1,195 \times$, p. $71-73$.

77 Voir .I. PY, Les fouilles de launage el les infuences grecques en riaule méridionale, dans liev. études ligures, XXXIV, 1965 IIommage a $F$. Benoil, II, 1973, p. 57-106, et notamment p. 60 et s. 
Baudinard et La Liquière ${ }^{78}$ et les vases rhodiens de Saint-Blaise, de la Couronne et du tumulus de claps. La plupart de ces pièces forment un groupe centré sur la basse vallée du Rhône, dans lequel s'insère normalement la Grotte Suspendue, sans qu'il soit nécessaire d'invoquer une autre cause, telle que l'existence dans les gorges du Gardon d'une voie privilégiée de pénétration du commerce méditerranéen.

Enfin, il convient de mettre l'accent sur le type d'habitat en grotte dont témoignent ces gisements ${ }^{79}$. C'est un mode d'occupation qui implique des groupes plus réduits d'individus et une dispersion plus grande des habitations que sur les oppida. Il faut aussi insister sur le caractère épisorlique et non exclusif de ce type d'implantation humaine, que la fouille de la Grotte Suspendue met en lumière. Il semble que dans les gorges du Cardon, l'occupation du Premier Âge du Fer soit la dernière attestéc avant la réoccupation du Bas-Empire, comme l'indique un hiatus archéologique de près de huit siècles. İ l'ìge du Fer, il s'agit de l'aboutissement d'un phénomène traditionnel, tandis qu'à l'époque romaine tardive, le retour dans les grottes est lié à des accidents historiques ${ }^{80}$ et inaugure un processus nouveau.

André Coste, Bernard 1)enet, Xavier (itThenz ot Wichel PY

$7 x$ Comme nous l'avons signale, il convient de ne pas tenir compte des lessons dits protocorint hiens de la grotte de Saint-Vérérleme.

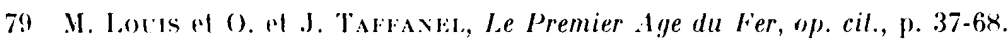

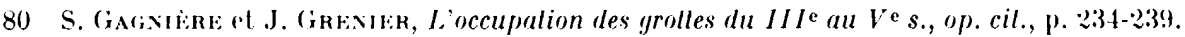

